\title{
Developing a smart multifunctional outdoor jacket with wearable sensing technology for user health and safety
}

\author{
Hyunseung Lee ${ }^{1}$ (D) Kyungsoon Baek ${ }^{2}$
}

Received: 16 July 2020 /Revised: 8 June 2021 / Accepted: 15 June 2021 /

Published online: 28 July 2021

(C) The Author(s) 2021

\begin{abstract}
Over the decades, there has been a sustained effort to use fashion as a medium for delivering digital functionality. The goal is to integrate information technology (IT) into clothing to provide users with functions to assist them in their tasks. Regarding the direction of previous efforts, this study developed a multifunctional smart outdoor jacket prototype that senses, recognizes, responds, and manages various safety risks and potentially hazardous situations and identifies environmental factors that are difficult to predict. The prototype's research and development (R \& D) was carried out through the following steps. First, to determine functions that can practically assist users in outdoor environments and help ensure their health and safety, a user requirement survey subject to expert evaluation was conducted. Six functions were selected: (1) Bluetooth hands-free calling and audio streaming, (2) heart rate monitoring for self-health care, (3) emergency calls to request assistance, (4) temperature-reactive heating to retain body heat for survival, (5) fall detection and automatic emergency calls, and (6) ultraviolet monitoring for self-health care. Next, a wearable system and its garment platform were developed, containing detachable device modules for washability and ease of maintenance. Lastly, a dedicated smartphone application was developed for extended functionality. By exploring the use of clothing in diversifying wearable health care and HAR systems, the study could be used to diversify wearable healthcare and safety platforms.
\end{abstract}

Keywords Technological convergence - Engineering - Multifunctional fashion · Outdoor fashion · Smart fashion $\cdot$ Wearable technology

Hyunseung Lee

hslalpha@daum.net

1 Department of Fashion Industry, Incheon National University, Incheon, South Korea

2 Modular Smart Fashion Platform Research Center, Kookmin University, Seoul, South Korea 


\section{Introduction}

Mann [32] introduces the concept of wearable computing to use clothing as a medium of delivery of digital functionality that began in the 1960s [8]. The idea behind Mann's concept is to assist users in their work and daily tasks using devices placed at the closest possible distance from their bodies. Meanwhile, the emergence of smartphones capable of complex computing in the mid-2000s has made mobility an essential computing requirement. These ultra-portable minicomputers' popularity allows users to browse the Internet, check their emails, watch videos, and stream music, which has rekindled interest in wearable computing. Leading information technology (IT) firms such as Apple, Samsung, and Fitbit started to develop wearable devices linked to smartphones worn on the body for hands-free computing [34, 37].

Moreover, to increase their appeal to consumers, today's wearables are produced as attractive fashion accessories such as watches, eyeglasses, and rings, leading tech companies to further expand into fashion accessories. To emphasize the wearables' fashionable side, growing numbers of tech firms are collaborating with fashion companies. For example, Apple solidified its position as the wearable market leader by collaborating with Hermes and Nike [9, $49,56]$. The recent advances in augmented reality (AR) and virtual reality (VR) technologies will expect wearables and other products based on the convergence between IT and traditional industries to hit the market in increasing numbers and variety [43]. Such a new direction in the IT industry has enormous implications for the fashion industry, and this direction is likely to have a significant impact on its product development strategy, giving it a new role and value $[25,26,57]$. Compared to other fashion items, clothing has many unique characteristics that make it particularly suitable as a wearable platform. Clothing, considered people's second skin, is more constantly present on the body than other fashion items. Technology can be integrated into clothing to augment its basic functionality, turning it into a mobile platform supporting sensing and an interface with context-aware computing [10, 12, 14, 50]. Moreover, the wearable system can be linked with a smartphone to provide certain computing functions that can interfere with clothing's basic requirements, such as comfort or wearability. By having the smartphone process complex data and using it as a display device, only essential and specific functions can be directly integrated into the garment platform [30, 40].

This study explores a new role for fashion that embraces wearable electronic-digital functions; functional clothing was an ideal topic for smart fashion research as these types of clothes are worn for specific purposes to meet particular requirements. Currently, smart clothing's design direction for the convergence of the fashion and IT product markets had moved toward physical monitoring, sports, and personal health care [40, 49]. Among the various types of functional clothing, outdoor sportswear is of particular relevance for the study's purposes because outdoor environments are, by nature, more unpredictable and can expose explorers and athletes to unforeseen situations with safety implications. People who engage in outdoor adventures, leisure, or sporting activities to enhance health and fitness are more liable to perform physical exercises that are excessively strenuous and stressful for their bodies without realizing it. Coupling the traditional functionality of clothing with digital functionality can provide a wide range of benefits, including increasing user motivation for outdoor or sporting activities, enhancing performance and comfort while ensuring safety from health or external risk factors.

This study developed a multifunctional smart outdoor jacket prototype with a series of functions designed to help its wearers manage hazardous or risky outdoor situations by sensing and identifying potentially dangerous environmental factors to prevent accidents and injuries. 
The study aims to create a multi-channeled wearable HAR system using clothes as a platform that can measure a user's heart rate and body heat while analyzing its user's state of activities and environmental factors. This step was followed by an investigation for the optimal garment platform design and technical design that enables the selected functions. The wearable operates in conjunction with a smartphone to delegate complex computing processes and use it as a display screen, reflecting the latest research and development ( R \& D) trend in wearable technology to avoid sacrificing comfort and ease of movement. The digital system components installed in the garment platform are kept as compact as possible without interfering with the system's functionality during the technical design process. The research process consisted of four stages, as described in Fig. 1.

\section{$R \& D$ concept development}

- Case study on existing smart-outdoor-sports wears.

- Investigation (survey \& interview) on Electronic-digital functionalities for outdoor-

sports activities and environment.

\section{Primary studies on R\&D of garment platform and functions}

- Configuration of the locations of each functional system module regarding the inter-connected relation between user's body and effectiveness of system operation.

- Investigation on the expensive functionality through the co-operation between wearable systems and smartphone, and configure the target functions of wearable systems.

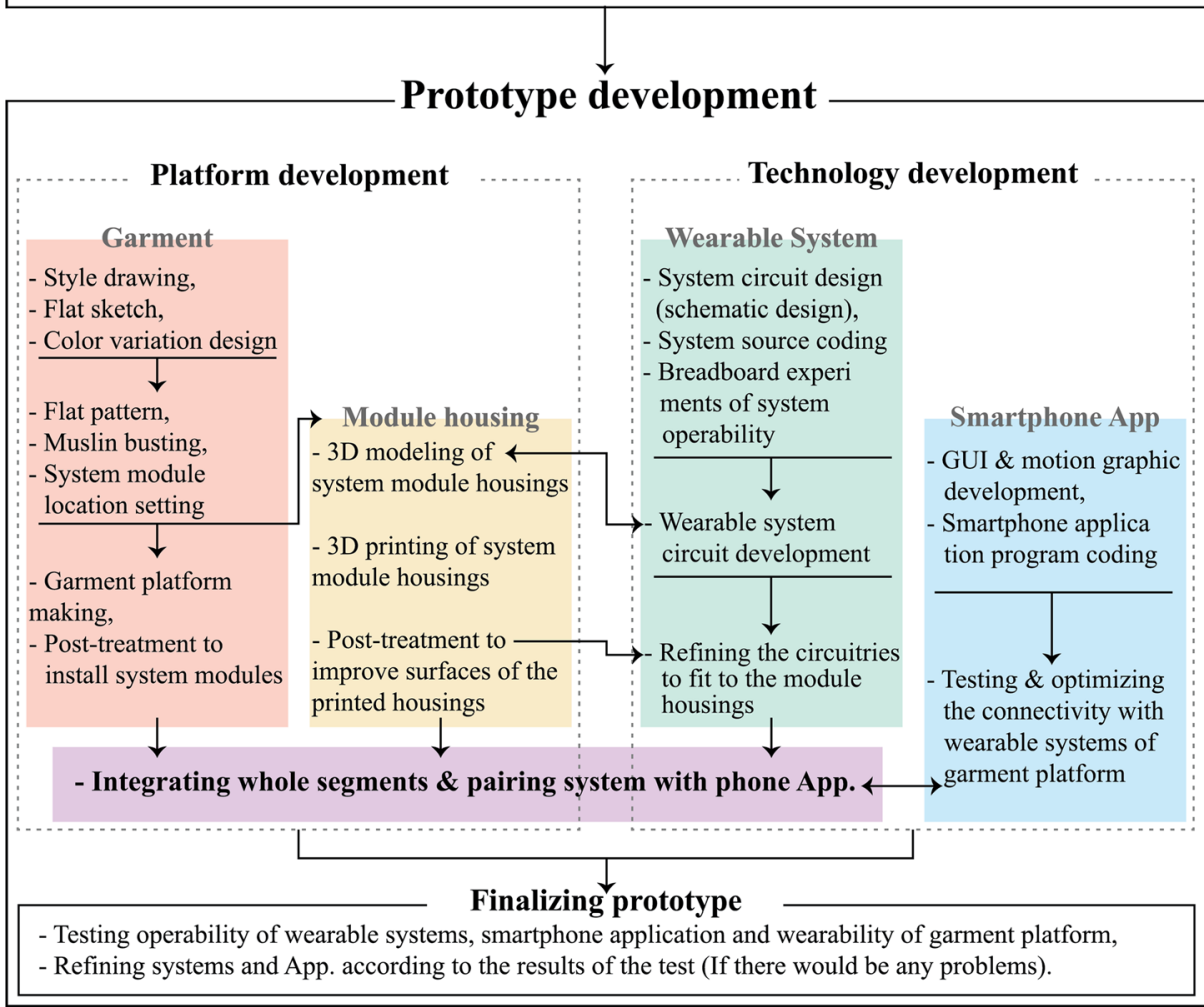

Fig. 1 Research model of this study's design process 
Existing smart clothes for outdoor adventures and sports were examined during this study's initial stage to define the smart outdoor jacket prototype's functionality range. First, a user requirement survey identified a series of functions selected by examining existing products. Next, the functions selected by users through the survey were presented to three experts (a wearable technology researcher, a fashion business professional, and an outdoor and leisure expert) to finalize the list of the system's functions. Six functions were selected: (1) Bluetooth hands-free calling (BH), (2) heart rate monitoring (HM), (3) emergency calls (EC), (4) temperature-reactive heating (TH), (5) fall detection and automatic emergency calls (FE), and (6) ultraviolet (UV) monitoring.

The second stage saw the prototype's preliminary design by mapping the configuration of functional modules installed in locations that are least likely to cause discomfort to the wearer or hinder movement. The design considered the planned method of attaching the modules for easy removal and better washability of the garment platform. This stage also saw the completion of the garment platform's concepts and basic designs and the smartphone application that provides extended functionality.

Based on the overall R \& D concept and the basic designs defined and created during the second stage, the multifunctional outdoor garment platform, device module housings, wearable system circuits, and the smartphone application were designed and developed in the third stage. At the final stage, the prototype was tested outdoors to verify the garment platform's wearability and the functionality of each system component and the software application.

This study's R \& D focused on two points. The first explored the garment's capability of combining traditional functions such as protection and aesthetics with digital functions to assist the user through the wearable system's modules. The second expanded the system's connectivity with smartphones to enhance the hands-free automatic operation to help the user while partaking in outdoor activities.

\section{Review on wearable technology and smart outdoor wear}

\subsection{Wearable technologies for fashion application}

Mann [32] introduced the concept of wearable technology in the 1960s. However, its technical realization had to wait until the 2000 s, when significant advances were made in mobile communications technology. The advent of affordable compact and light mobile devices gave a new impetus to wearable research with related R \& D actively undertaken by the industry, academia, and government research institutions. The effort to develop wearable devices worn close to the body to assist users in their work and daily tasks by extending their cognitive and physical abilities led to the emergence of smart clothing integrated with various wearable technologies. Land Warrior (smart military uniforms developed by the US army) and Life Shirts (medical clothing developed by Vivometrix) are two well-known examples [19, 42]. Many wearable technology researchers have shown a keen interest in clothing as a wearable platform as garments are nearconstantly worn and sit closer to the skin than any other items worn on the body. Clothing and wearable research aims to harness garments' potential benefits, such as near and constant presence and mobility. These topics focused on designing and enabling functions optimized for specific purposes simultaneously while augmenting their fundamental roles. Currently, key paradigms in clothing and wearable research include wearable sensing (body sensing), context-aware computing, wearable interfaces, and augmenting traditional functions of clothing $[10,12,14,33,50]$. 


\subsubsection{Wearable sensing}

Wearable sensing technologies allow users to measure their vital signs from a wide range of body parts and recognize their body movements $[14,33]$. Alternating the sensors' types or locations can change the sensing targets from the users' body conditions to the environmental situations [18]. Wearable sensing, commonly applied in healthcare sensing or human activity recognition (HAR) technologies, was investigated to adapt in medical fields and sports and gaming $[11,47]$. In particular, wearable sensing for sports activities contains sensors embedded in clothing, which measure a users' motion loads to control the intensity of exercise and motivate physical exercise by providing calorie consumption data [11]. Composite sensors' technological advancement like electromyogram sensors can monitor muscle and body movements for sports care or coaching purposes $[11,55]$. Moreover, clothing-embedded sensors can utilize the same sensors to deduce users' location, activities, and even emotional states [20, 51]. Thus, context-aware computing is a technology for user-centered wearable sensing to recognize environmental information [14, 27].

\subsubsection{Context-aware computing and wearable interfaces}

Context-aware computing possesses a large part of ubiquitous computing or pervasive computing in wearable terms. It means spaces and objects become intelligent and, at the same time, independent $[12,14]$, similar to how the current concept of the Internet of Things is understood $[16,31]$. As the computing environment has migrated from desks to human bodies in the form of wearables, suitable input-output interfaces should be developed for contextual information, like sensing a user's body information or the environmental circumstances around him/her [14]. During the diversification of wearable technology investigation from the 2000s to the 2010s, previous research suggested tactile or gesture-based interfaces as the suitable input-output interfaces of context-aware computing for wearable systems $[10,12,50]$. As gesture-based input and tactile-based output feedback do not rely on a user's visual sense than traditional computing interfaces, users can intuitively react to feedback by performing physical activities that need their visual senses.

\subsubsection{Augmentation of traditional fashion's functionality}

Furthermore, wearable technologies can augment fashion's fundamental role and functionality, such as basic protection and aesthetics [14, 42]. For example, in the electronic heating function developed to augment clothing's thermal protection in 1968 [14], users no longer needed to repeatedly wear and remove thick clothes to react to temperature changes by manipulating function control switches on clothing platforms. The aesthetic aspects of fashion can also be augmented through a similar principle as an individual's expressive or aesthetic preferences can change dramatically in a day. Users may control a garment's appearance, such as its shape, color, or graphics, via kinetic (motor) and lighting (light-emitting diode) technologies. As seen in the collections of designer Hussein Chalayan and British fashion brand Cute Circuit, technology augments fashion's aesthetic or adorning role [5, 14, 24].

\subsection{Wearable technologies for outdoor activities and the environment}

Mountaineering, tracking, and hiking in mountainous terrains allow people living in modern societies to temporarily escape from their daily routines and strict social structures, providing 
them with an opportunity to physically and mentally recharge themselves. Today, increasing numbers of people engage in outdoor and leisure activities in the wild environments such as mountainous terrains [2,7], and these activities, although distinct from one another to some degree, all take place outdoors where people have to contend with the unpredictability of nature. The sense of accomplishment provided by these activities comes from taking risks and overcoming challenges. Unlike activities in a controlled setting like bungee jumping or amusement park rides, outdoor leisure activities involve unpredictable safety variables like fall injuries, fatalities due to steep, rugged terrain, etc. Outdoor adventures are challenging because they occur in unfamiliar settings and that the types of activities have little to do with what most people do in their everyday lives. People who engage in these activities are fully aware of the risks and challenges presented by the natural environment's unpredictability, the psychological reward of overcoming them, and health benefits [36, 45]. Some theories suggest that the higher the risk of serious or fatal accidents in an outdoor activity, the greater the sense of accomplishment experienced by its practitioner. In other words, people engaging in outdoor activities are prone to take greater risks for a greater sense of accomplishment, an impulse that further increases the risk of accident or injury [38, 39, 45].

Moreover, outdoor environments have numerous uncontrollable variables. Falls or other types of distress situations in mountains and high-altitude terrain can often lead to fatal injuries like skull, cervical, or hip fractures or hypothermia $[35,36,45]$. Therefore, the wearer's health and safety are essential considerations for a wearable system. Health monitoring and safety technology, allowing users to check their vital signs and alerting them about potentially dangerous situations, can be especially effective if sensors are placed inside a garment. This technology will make outdoor activities safer, motivate users, and help them achieve their fitness objectives, increasing their sense of accomplishment. These considerations have been the common direction of $\mathrm{R} \& \mathrm{D}$, whether by the fashion industry or academia, on wearable technology-based smart wear applications for outdoor use, even if the types of technology have changed over time.

The Burton Motorola Audex down jacket is an outdoor sportswear jacket for winter sports with pockets with built-in cell phone and iPod ( $\mathrm{mp} 3$ player) ports. The wearer can control the cell phone or the iPod without taking it out of the pocket using the control module located on the left sleeve. The control module, consisting of a liquid crystal display (LCD) screen and membrane switches, allows the wearer to adjust the volume and change audio tracks. Thanks to the hood's built-in speakers, the wearer can listen to music and stream content without wearing earphones or headphones [54]. The Life Tech jacket by the outdoor fashion company Kolon Sports, developed through collaboration with Seymourpowell, is a survival jacket for extreme weather and high-altitude regions like the Himalayas. Equipped with a thermal inner layer featuring a conductive polymer heating system, the Life Tech jacket lets the wearer choose between three heat levels (high $50{ }^{\circ} \mathrm{C}$, medium $45^{\circ} \mathrm{C}$, and low $40{ }^{\circ} \mathrm{C}$ ). The jacket has a built-in GPS for emergency geolocation and also comes with a wearable wind turbine generator for charging the GPS and mobile devices [46].

The SDJ (self-drying jacket)-01 by Falyon is equipped with a self-drying system designed to keep its wearers dry in wet outdoor environments or on rainy days and prevent moisture damage to the mobile devices they carry. The self-drying system is activated using the membrane switch located near the belt along the jacket's hemline. When turned on, the system activates a series of air amplifiers inside the jacket's lining, sucking in the humid air from the outside and dry it. After the drying process finishes and the system is shut off by the user, the vents located on the neckline release dry air [13]. Outdoor fashion brands such as Ororo and 
Raven have developed thermal outerwear lined with heat wire. Unlike traditional extreme weather jackets stuffed with thermal insulation, these jackets are slim while being just as warm or warmer. Most outdoor jackets are built with a similar heating mechanism. For example, the thermal system of the Ororo softshell jacket uses heating pads placed near the chest and in the central area of the torso, which is activated by a membrane switch located below the left shoulder, to provide a thermal performance that is superior to that of traditional extreme weather jackets. As electric heating is rather power-intensive, Ororo's thermal jacket comes with a removable $7.4 \mathrm{~V}$ secondary battery, which can also charge cellphones or other mobile devices using the built-in USB port inside the pocket [3, 4].

Aside from the previously mentioned outdoor products and cases, this study also referred to some related studies that dealt with sensing a user's activities concerning safety and aid. Park et al. [40] developed a smart outdoor shirt that monitors the wearer's heart condition using wearable technology. The Bioshirt clothing platform was developed according to the body proportions and sizes of people aged 40-69. Its wearable system, consisting of separate modules, is removable from the garment platform. The wearer's vital signs are measured using a contact-type electrocardiogram sensor built with metal electrodes and conductive fibers. The heart rate data is transmitted to the user's smartphone via Bluetooth to monitor cardiac status through a dedicated application [40].

A study conducted by Li et al. [28] investigated an Android smartphone application that improves pedestrian safety when staring at smartphone screens. They utilized the smartphone's built-in gravity sensor, accelerometer, and forward-facing camera to measure the user's walking speed and eye movement. When the user reaches a specific walking speed and the user's eyes still stare at the screen, the system generates vibrations that urge the user to pay attention to the road [28]. Meanwhile, Li et al. [29] studied the SmartJump smartphone framework, based on Android API, to recognize a user's jumping motions for exercise tracking. They used a built-in accelerometer and magnetometer in a smartphone to detect jumping motions and count the number of jumps performed. The framework consisted of three phases: jump sensing, data processing, and jump detection, which were based on z-axis acceleration data [29]. In comparison, Watson et al. [53] investigated the Magneto wearable motion tracking system to the user's elbow joint flexion for exercise tracking. In said study, the effects of the Earth's magnetic field on the measured data's accuracy a key research point, and a localized electromagnet was used to detect precise elbow joint angle changes [53].

Technologies used in the smart outdoor wear and user activity tracking research described above are summarized in Table 1, organized by the type of electronic circuit element (input, output, and control).

These examples show that smart outdoor clothing R \& D consistently focuses on practical functionality rather than entertainment functions despite the differences in enabling technologies. Besides the Burton Motorola Audex down jacket, the other examples' designs serve beneficial purposes such as body heat retention, GPS-based geolocation, heart rate monitoring, etc. However, most examples provide a single key function coupled with a few derivative functions. Most of them also require the intervention of the wearer to activate a function. In other words, wearables offering a broad range of smart functions or providing proactive functionality where the system automatically performs tasks based on the contextual understanding of surrounding environments and situations without users' intervention are still very much lacking. This study aims to develop a multifunctional wearable system platform with proactive functionality linked to a smartphone for extended functionality to address the shortcomings of existing smart outdoor wear. 


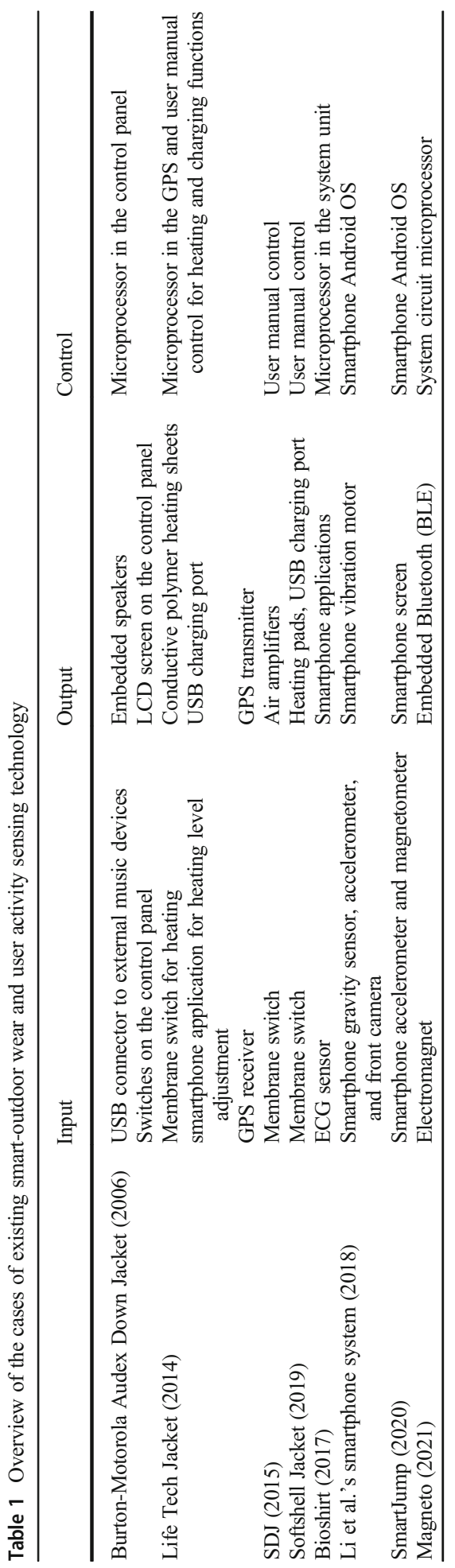




\section{Developing the multifunctional smart-outdoor jacket}

\subsection{Materials and methods}

A multi-channeled body sensing and activity recognition technologies are constructed and integrated into the clothing platform to provide health care and safety functions for outdoor activities that measure the user's vital signs and analyze the user's activities. Based on previous studies, their prototypes were developed to provide various functions, including heart rate monitoring, rear detection for the hearing-impaired, obstacle detection and warning for the visually impaired, and electronic heating for medical purposes [26, 27]. These studies used simple approaches to construct systems that provided one function using sensors to detect stimuli and display or alert the user using measured data without analytical processes that predict or perceive a user's physical situation. Previous studies were focused on developing wearable sensing systems for use in urban environments. However, more complex sensing and processing technologies are needed when developing a similar system that monitors user health and outdoor activities.

\subsubsection{R \& D concept development}

In developing multifunctional smart outdoor wear, the range of outdoor activities included intense activities such as climbing, light activities such as trekking, and other adventure and leisure activities to ensure the prototype's broad usability. As for the type of apparel, the garment platform chosen was a jacket. Many outdoor activities involve dynamic movement regardless of the types of activities and environments. If innerwear or bottom wear (pants) had embedded wearable systems, the system's devices could cause skin irritation and become damaged because of constant friction against the body.

On the other hand, outdoor jackets generally cover half of the wearer's body, ensuring free body movements, and their rigid fabric protects the wearer from external stimuli. A jacket was chosen based on the following advantages: its proximity to vital body parts such as the writs and the heart, the convenient manipulation of the system's digital interfaces, and the ease of equipping sensors and devices for data collection. Moreover, these sensors are directly exposed to external stimuli to recognize the wearer's surrounding environment [14, 25, 52].

Based on the activity-related and technical considerations, the user requirements survey determined the functions actual users need during outdoor activities, followed by expert evaluation. A total of 80 respondents, who were men and women in their $20 \mathrm{~s}$ and $30 \mathrm{~s}$, an age group that tends to have a high interest in smart devices [23], were surveyed using the Graffiti Wall technique. The questionnaire presented a series of functions present in wearable technologybased smart clothing and asked the respondents to choose only one. Experts from three fields related to the study's prototype development (wearable technology, fashion business, and outdoor leisure activities) reviewed the functions selected from the survey and provided their professional opinions on their usefulness and technical feasibility. Six functions were selected through this process, reflecting the $\mathrm{R} \& \mathrm{D}$ concept for the garment platform and the wearable system (Table 2).

The clothing platform's specifications and configuration were developed for ease of use because the prototype's functions aimed for user convenience, comfort, health monitoring, and emergency treatment while performing outdoor activities. As described in Table 3, the garment platforms' functional systems were designed and developed so that the user does not need to pay much attention to them during the outdoor activities. 
Table 2 Selected functions for this study's multifunctional smart-outdoor jacket R \& D

\begin{tabular}{|c|c|}
\hline Function (number of votes) & Function and usage \\
\hline Bluetooth hands-free functions (9) & $\begin{array}{l}\text { The assistive function allows the wearer to make hands-free calls, listen to } \\
\text { music, and stream content using the built-in microphone, speakers, and } \\
\text { Bluetooth system }\end{array}$ \\
\hline Heart rate monitoring (10) & $\begin{array}{l}\text { Healthcare function monitors users' heart rates during outdoor activities to } \\
\text { adjust the exercise intensity based on their physical condition. }\end{array}$ \\
\hline Emergency calls (15) & $\begin{array}{l}\text { A safety assistance function allows the wearer to alert healthcare } \\
\text { professionals or emergency responders upon experiencing symptoms that } \\
\text { require immediate medical attention. }\end{array}$ \\
\hline Temperature-reactive heating (10) & $\begin{array}{l}\text { A healthcare and safety assistance function that prevents hypothermia by } \\
\text { automatically activating a built-in heating system when the wearer loses } \\
\text { consciousness during outdoor activities in extreme weather conditions. }\end{array}$ \\
\hline $\begin{array}{l}\text { Fall detection and automatic } \\
\text { emergency calls (13) }\end{array}$ & $\begin{array}{l}\text { Safety assistance function activates when the wearer loses consciousness } \\
\text { from falling. Emergency calls are automatically made to alert emergency } \\
\text { responders. }\end{array}$ \\
\hline UV monitoring (7) & $\begin{array}{l}\text { Healthcare function monitors UV radiation to protect the wearer from } \\
\text { harmful UV levels. }\end{array}$ \\
\hline
\end{tabular}

A major trend in wearable technology and its application is meeting a wearable system's computing needs through a smartphone. Therefore, exploring new functional possibilities of smart fashion by focusing on practical benefits of wearables and user needs, rather than the system's computing capacity, appears to be a valid approach in line with the current industrial and technological trends $[11,40]$. Moreover, R \& D on smart fashion must not hinder clothing's traditional functionality while serving as a wearable platform $[22,50]$. The latest trend in the development of smart wearables consists of integrating small electronic modules into platforms that are otherwise traditional, both in designs and materials, as exemplified by the Nike+ smart running shoes. System modules have their electronic circuits placed inside housings developed using a numeral control milling machine or 3D printing technology and installed into the garment platform so that they can be easily removed and reattached as needed $[11,25,40]$. This assembly uses significantly fewer wires and cables than traditional electronic products, making them less visually obtrusive while increasing the system components' durability.

On the other hand, there were concerns about the aesthetics of the modularized housings on the garment's surface. Three modeling and printing areas were investigated for the modules' housing designs to address this concern, enhancing the garment platform's wearability and washability. Therefore, three objectives were set for this study.

The first objective is to develop a multifunctional wearable system based on wearable sensing and context-aware computing technologies to provide practical functions to assist users in their activities in outdoor environments. Second, the study must modulize the wearable system for each component's independent operation and devise an installation method that allows easy removal and reattachment, helping maintain the garment platform's traditional usability. Lastly, to develop a smartphone application that provides extended functionality to the wearable system.

\subsubsection{Developing the garment platform}

Platform design process Inaccurate readings by embedded sensors can occur in wearable sensors built for healthcare purposes [48]. Consequently, garment platforms were composed of a skintight silhouette to maintain the proximity between the users' bodies and sensors to 


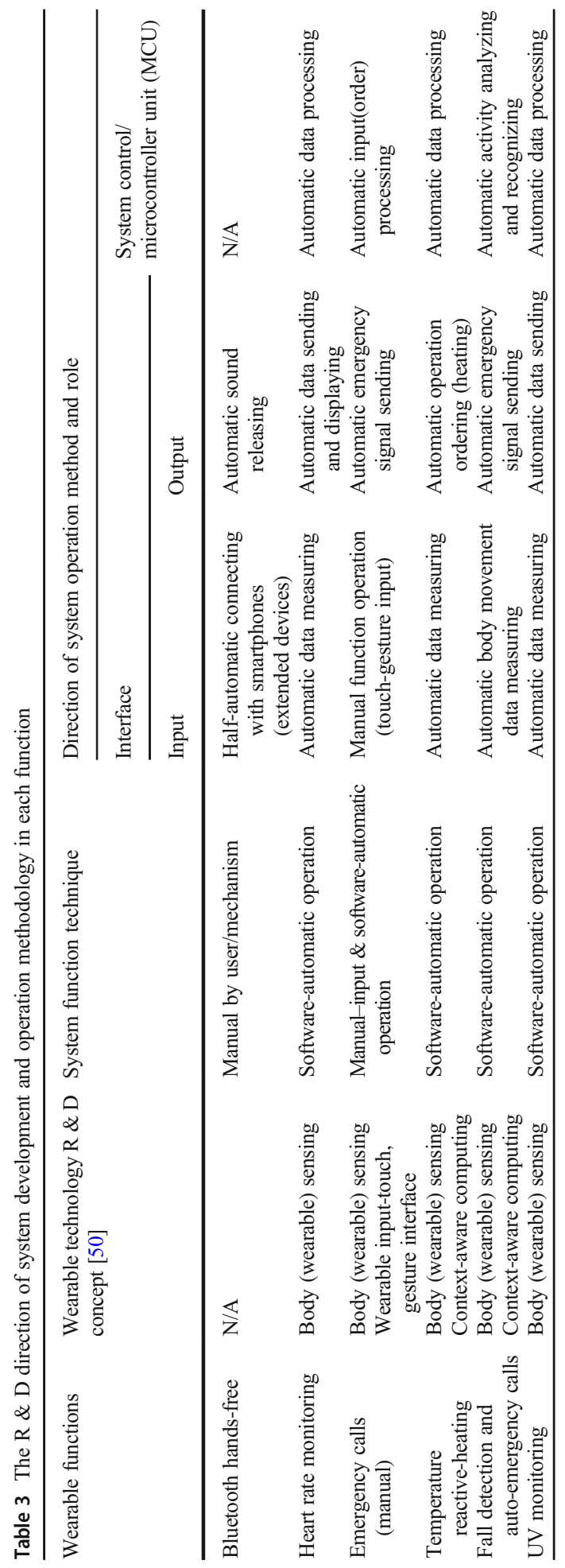


minimize the external variables in sensing $[14,57]$. These skintight shapes, however, would not be physically and socially comfortable [15]. Moreover, it is inappropriate for outdoor wear to activate the wearers' activities and protect their bodies from external physical stimuli. Based on these fashion and technical considerations, several criteria for designing this unisex garment platform were selected.

First, the garment platform design must reflect the current (fall-winter 2019) outdoor sports fashion trend and offer plenty of spaces to carry essential tools for outdoor activities. Second, when integrating the six functions into the garment platform (Bluetooth hands-free calling, heart rate monitoring, emergency calls, temperature-reactive heating, fall detection, automatic emergency calls, and ultraviolet (UV) monitoring), the device modules must avoid interfering with the user's movements while allowing each system component to function optimally. The components must be easily removed and reattached. Third, the function module housings' designs were streamlined and rounded to mediate the platform's aesthetics upon attachment to ensure the garment's traditional functions.

The garment platform's design and development focused on the aesthetic and functional standards of outdoor fashion, and the design considerations on the platform's appearances are as follows. Of the currently popular styles, oversized silhouettes are particularly well suited for wearable platforms, which require room to fit in electronic components needed to integrate technology. The garment platform's initial designs started with an oversized silhouette larger than regular outdoor jackets by reinterpreting the body's skeletal system, applying simplified lines, and adding a hood, multiple inner and outer pockets in shapes suitable for their respective locations. For color combinations, several commercially available outdoor jackets were chosen to reflect up-to-date color trends (Fig. 2). The platform's final design and color combination were chosen through discussions with the three experts previously consulted while defining the $\mathrm{R} \& \mathrm{D}$ concept and considered while designing the wearable system modules. Draft design C (Fig. 2) was selected, which has two outer pockets on either side of the chest and the shoulders, with two large pockets below the chest.

Along with design considerations, the study also investigated the platform's functionality through traditional fashion approaches to enhance its usability as an outdoor garment augmented by digital devices. For platforms intended for outdoor use, a sufficient number of pockets are needed, and the outdoor jacket should have a hood because the Bluetooth handsfree $(\mathrm{BH})$ modules should be near the wearer's head. For the jacket's breathability and the wearer's comfort, two-way zipper closures were added to both sleeves and along the side seam lines to provide airflow into the infra-axillary area where sweat can collect during intense physical activities. The garment platform's color is solid black (Fig. 3) because it absorbs more radiation from the sun than other colors, helping the body retain heat, albeit marginally, under extreme weather conditions. Although black has the disadvantage of low visibility at night, other colors are not significantly superior in terms of nighttime visibility unless artificial light

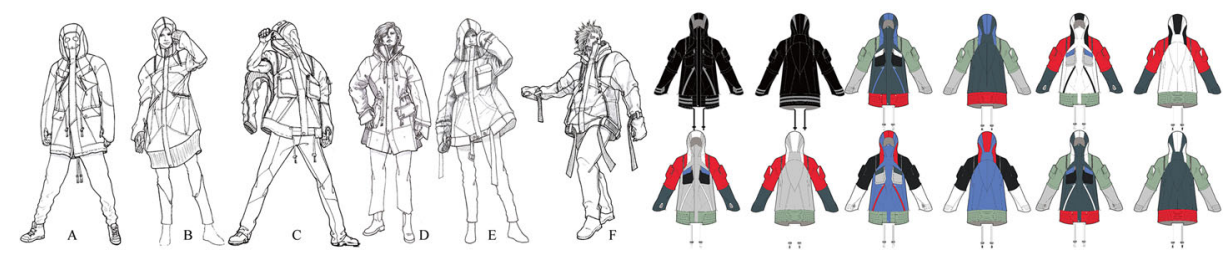

Fig. 2 Sample images of design and color variation development 

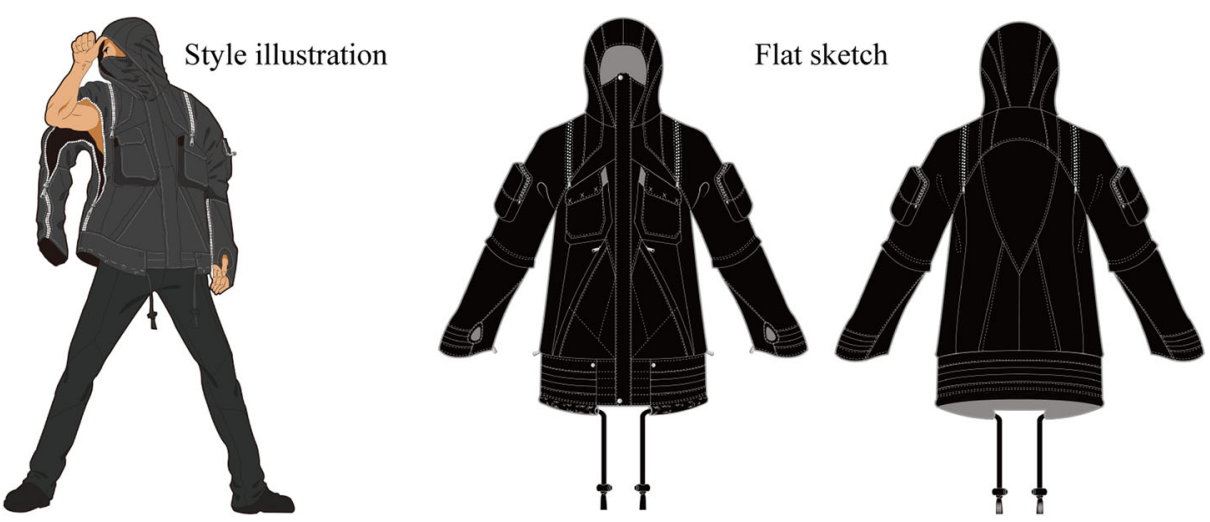

Fig. 3 Selected design of the garment platform

is present. Integrating LED lighting into the garment can enhance visibility so that the distressed wearer can be easily discovered even at night.

Platform construction process The platform was constructed to house six function modules in specific locations. The Bluetooth hands-free module is located on the left side of the hood to reduce the use of electronic wires connected to speakers close to the user's ears. A UV monitoring (UV) module was located in the out pocket on the right side of the chest; the temperature-reactive heating $(\mathrm{TH})$ function's control module was located in the left chest out pocket. Meanwhile, the two-in-one module integrating the heart rate monitoring (HM) and emergency-calling (EC) functions was located near the left sleeve cuff. The fall detection (FA) modules were located separately in the upper side of the front hemline (accelero-gyro module) and the upper-middle side of the back (DMS module) (Fig. 4). Table 2 and Fig. 4 indicate the specific functions and locations on the platform.

While drafting the flat pattern, the locations of module housings, which contain various functional circuits, were marked by drawing their shapes in their actual sizes. A muslin mockup was created to test the holes' positions for the system modules, produced through 3D printing, and the Velcro anchors for their functionality. The mockup was then fitted on a
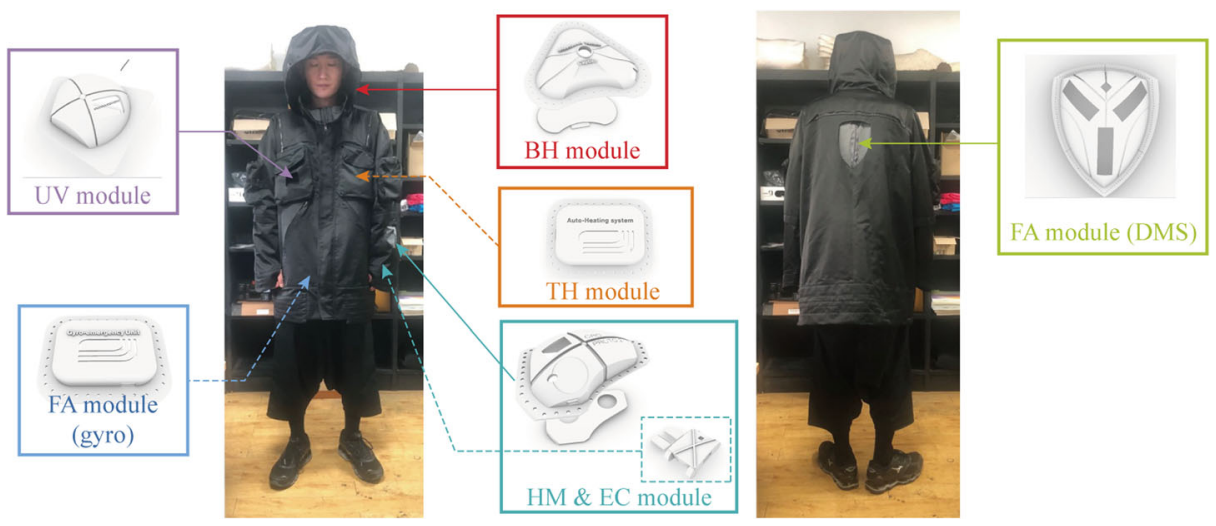

Fig. 4 Finalized garment platform and the locations equipping each system module 
model to check whether it matches the design intent in terms of silhouette, length, complex lines, and details like the sizes and positions of outer pockets. The fitting process also checks whether the modules selected for the system modules are intended and match the modules' shapes and sizes. The flat pattern was revised to reflect any design issues or errors in locations of the system modules discovered during the fitting, and the constructed platform was based on the finalized pattern with the correct locations of the modules (Fig. 4). In the locations of the system modules of the garment platform, the blank spaces and Velcro assembling lines were applied to equip the module housings (Fig. 5).

\subsubsection{Developing functional systems}

System design and development Given the numerous functional modules loaded into the garment platform, devices that can minimize the modules' size and weight while providing sufficiently high technical specifications were prioritized. Among the smallest and lightest devices available to the research community, Tiduino, an ultra-compact microprocessor compatible with Arduino, measuring $20 \mathrm{~mm} \times 20 \mathrm{~mm}$, and Bluno Beetle, an integrated Bluetooth low energy (BLE) board, measuring $28.8 \mathrm{~mm} \times 32.1 \mathrm{~mm}$ were selected. The system allows alternating uses between Tiduino and Bluno Beetle depending on each component's functional characteristics by selecting the control, input, output, and power devices accordingly (Table 4).

First, installing the hood's module caused the center of gravity to shift toward the module unless it is ultra-light and compact. Therefore, the system was constructed using a control board with integrated BLE sound control chipsets, measuring $20 \mathrm{~mm} \times 40 \mathrm{~mm}$, and the smallest possible $3.7 \mathrm{~V}$ lithium-ion battery $(20 \mathrm{~mm} \times 25 \mathrm{~mm})$. No circuit schematic was drawn up for the $\mathrm{BH}$ function, as the integrated Bluetooth sound control board only needs to be connected to the speakers and the battery, making any further circuit design unnecessary.

Second, the HM and EC functions were consolidated into a single module placed at the bottom of the left sleeve, deemed the best location based on their purpose and the components' functional characteristics. A small, portable optical heart rate sensor, commonly used for monitoring heart rates in outdoor environments, was also used in this study as the input device for the HM function. For maximum efficiency and accuracy of measurements, the optical heart rate sensor was placed as close as possible to the user's skin. The sensor was designed like a watch, as a detachable module worn on the left wrist, which is an area that is barely affected by
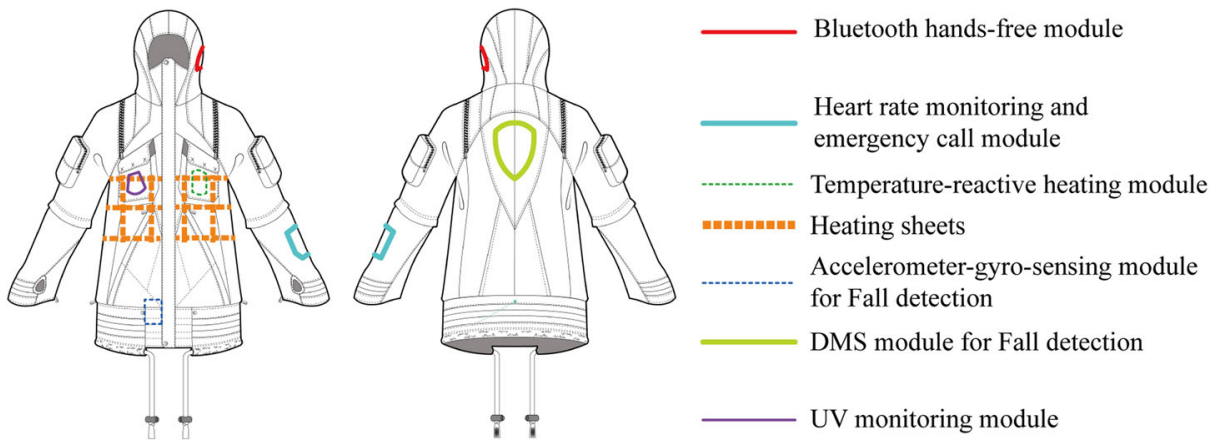

Fig. 5 Velcro lines inside the garment platform 


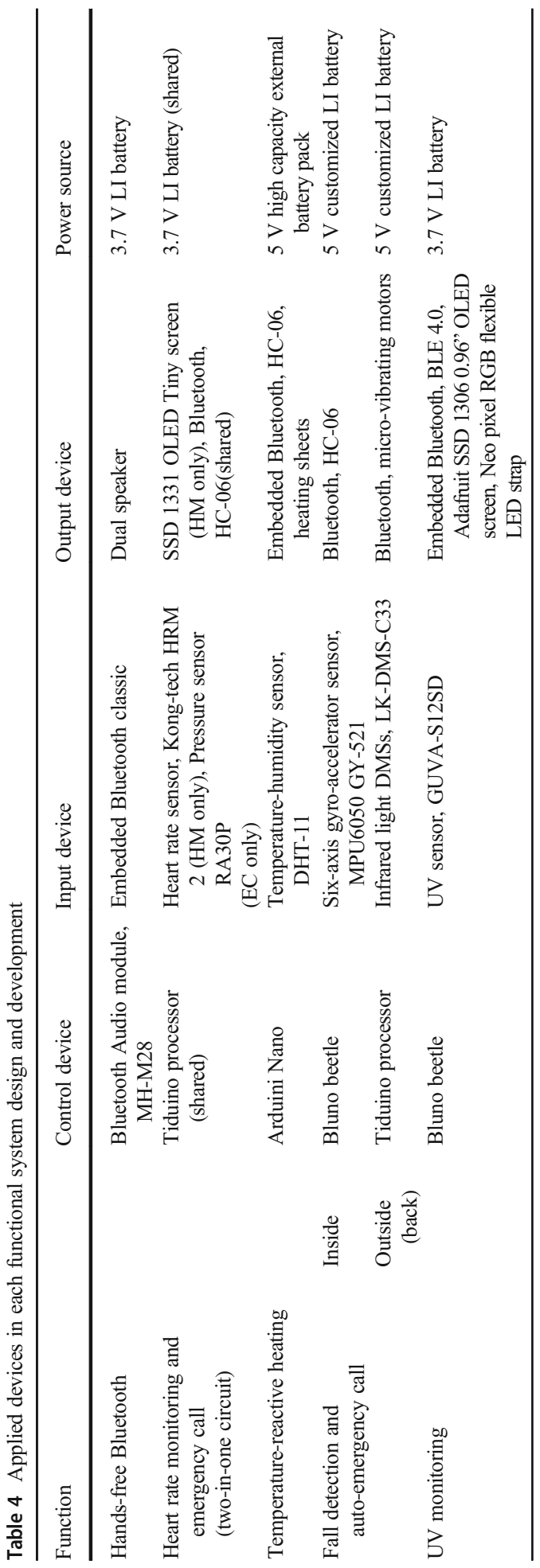


the wearer's activities. The HM system was designed to perform similarly to a high-accuracy ECG, consisting of two channeled stereo wet electrodes attached to the user's skin to detect heart rate (PSL-iECG2), and the code that measures and calculates the heart rate values was meticulously adjusted to match established value ranges.

Meanwhile, the HM control module was positioned at the bottom of the left sleeve to reduce the distance between the sensor and the control module and minimize any negative impact caused by user activities on the system's durability. The EC function allows the wearer to quickly make calls and send texts to request emergency assistance by touching the HM module's surface on the left arm, which the pressure sensor recognizes to make calls and send texts. Therefore, the EC device and the heart rate monitoring sensor form a single module, placed at the bottom of the left sleeve, and the program's source code allows a single processor to control both of these functions. This dual-function system's circuit was constructed with Tiny Screen $(25 \mathrm{~mm} \times 32 \mathrm{~mm})$, an ultra-compact organic light-emitting diode (OLED) display compatible with Tiduino for use with the HM module, along with a Bluetooth 3.0 module, heart rate sensor, a pressure sensor, and a $3.7 \mathrm{~V}$ lithium-ion battery (Fig. 6).

Third, the TH system uses a high-capacity ( $2 \mathrm{Ah}$ ) external battery rather than a regular built-in battery commonly used in mobile devices to extend this power-intensive component's duration. The system reacts to drops in body temperature and maintains it even without the user's intervention. Its circuit comprises a BLE module, Bluno Beetle-integrated board, a temperature sensor, a metal oxide semiconductor field-effect transistor (MOSFET) module, 8 heating sheets, and a $5 \mathrm{~V}$ and 2 Ah high-capacity external battery. For the TH system's control module to obtain accurate measurements, the module was placed in the left chest pocket,

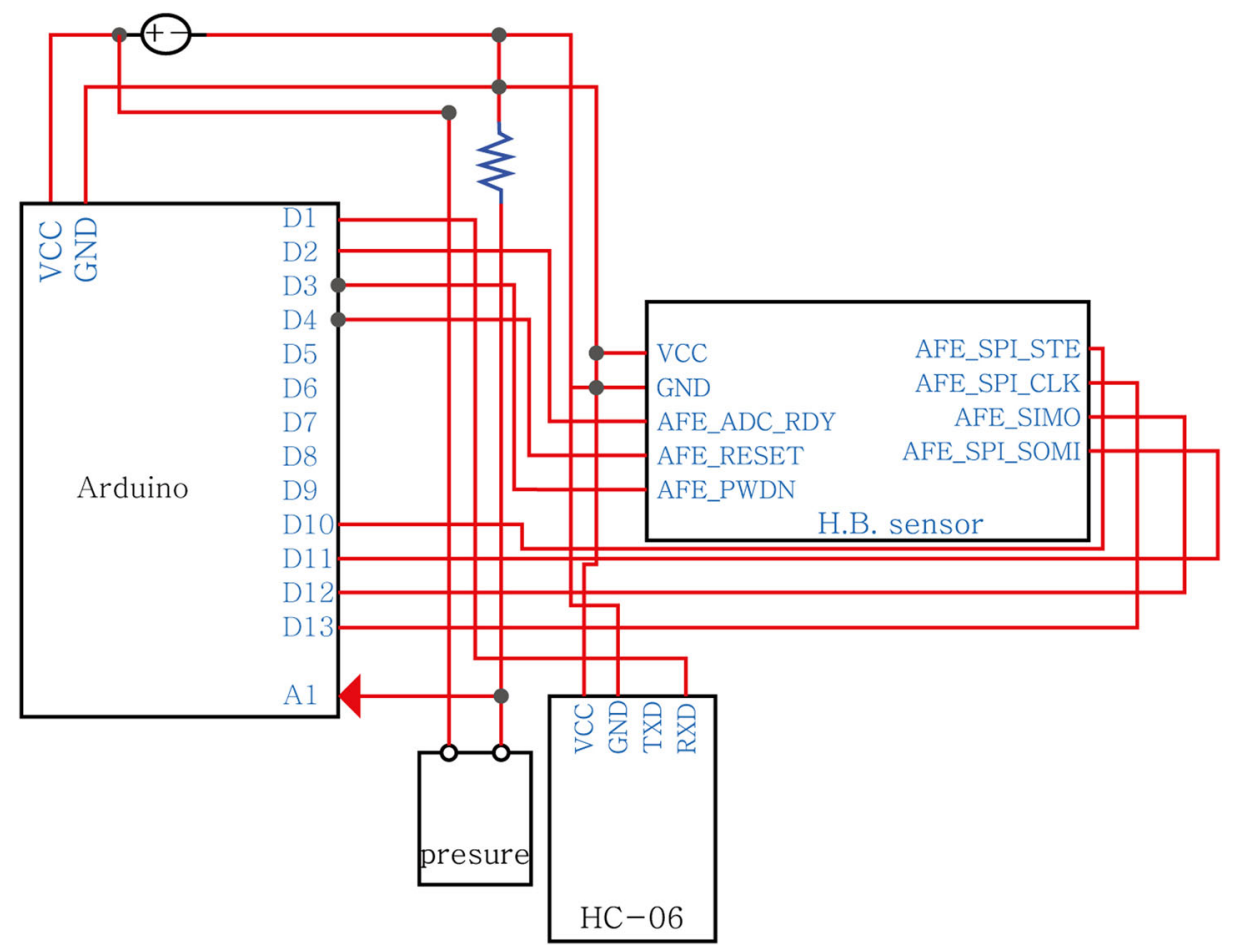

Fig. 6 Schematic diagram of the heart rate monitoring (HM) and emergency calling (EC) two-in-one circuit 
shielding the temperature sensor from the external atmosphere. Meanwhile, eight heating sheets (four in the front and four in the back), placed near the heart, provide ample heating to maintain the body temperature (Fig. 7).

The MOSFET module controls the external battery's current because 2 Ah was unsuitable for the Bluno Beetle microcontroller unit (MCU) and sensor units' electronic stability and durability. Operating the TH module was comprised of two stages. Initially, the MCU detects the body temperature and releases the heating sheets' operation signal when the temperature was lower than the configured standard temperature $\left(13^{\circ} \mathrm{C}\right)$. Next, the battery's maximum current is supplied to the eight heating sheets through the MOSFET module, activating the heating function (Fig. 7).

Fourth, the fall detection and automatic emergency call (FA) system has two different system modules to reflect the diversity of outdoor environments, unlike the HM and EC functions integrated into a single module. For flat and gently sloped areas, a 6-axis gyro accelerator sensor will recognize the user's activities. The sensor recognizes the velocity of body movement and the body's angle, detecting a fall from a high place by its angle and acceleration. When a fall is recognized, this prompts the built-in Bluetooth module to make calls and send texts to request emergency assistance. The module is placed at the bottom of the

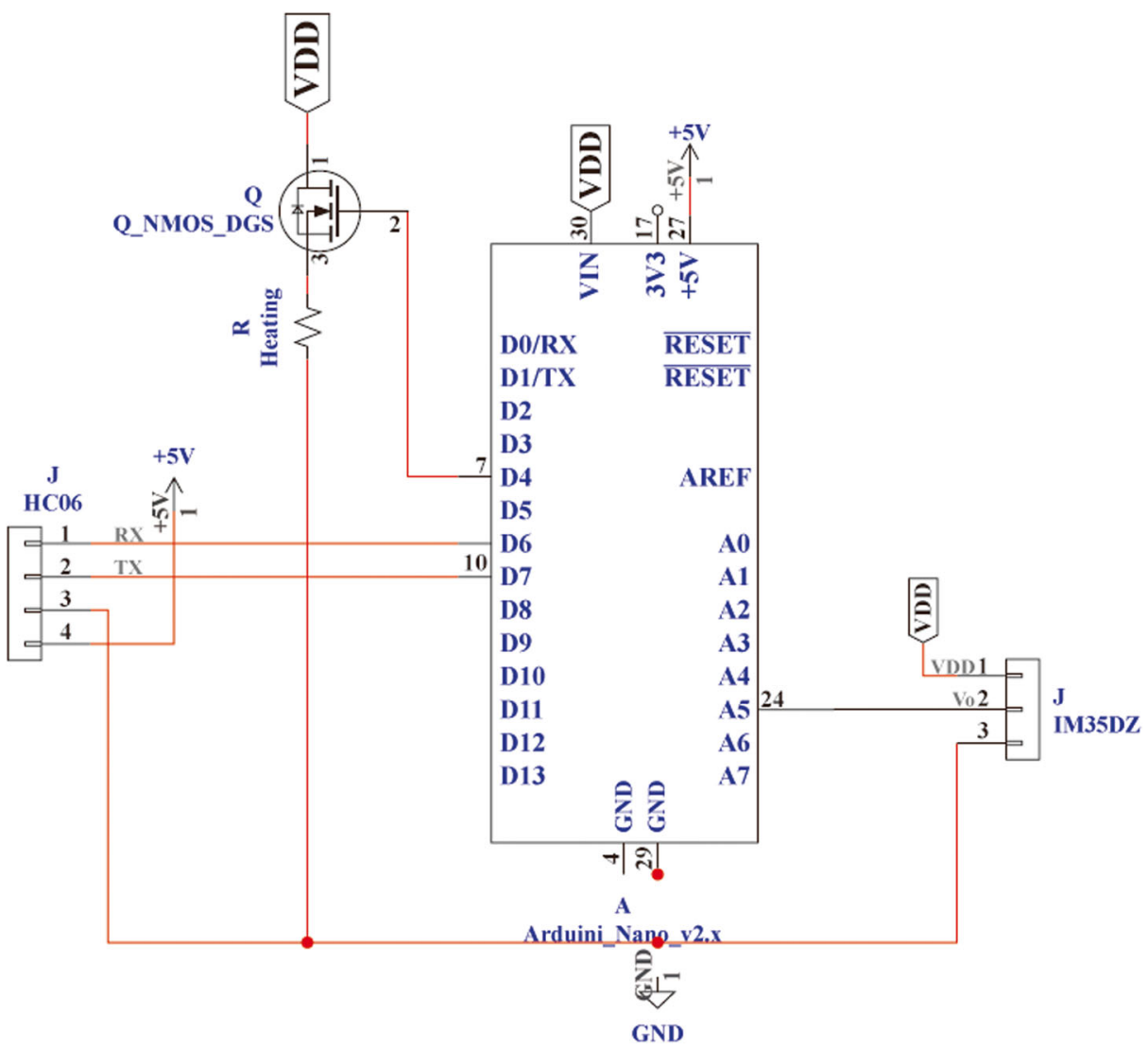

Fig. 7 Schematic diagram of the temperature-reactive heating $(\mathrm{TH})$ circuit remade with a metal oxide silicon field-effect transistor (MOSFET) module 
body's center to ensure the system does not respond to normal movement during outdoor activities, like a normal forward bend. In mountainous areas, if the wearer gradually slumps into a position with his back leaning against a slope, the angle and the acceleration pattern may not be clear enough for the gyro sensor to recognize. An infrared distance measurement sensor (DMS) compensated for this limitation in steep, rugged terrain. The DMS senses the rear areas (center rear, left rear, and right areas) behind the user to measure the user's actual distance and the fall location. The DMS sends out alert signals when the user's rear approaches the ground or other structures to almost touch it (a distance of 15-30 cm). An extra assistive distancebased function makes more productive use of the DMS installed on the garment's rear. When an object is approaching from behind (from a distance of 3-18 m), the built-in vibration motor is activated to alert the user at specific distance increments. The system circuit was built with Tiduino, whose communications port has more pins than Bluno Beetle (Fig. 8), which allows the installation of three DMSs for sensing three directions and a vibration motor.

Fifth, the UV module was installed outside the right chest pocket, sufficiently and constantly exposing the UV sensor to the sun, which is necessary for optimal measurement accuracy. As UV radiation is not a stimulus that humans can sense, a screen displays its intensity for the user and his/her companions. The screen with a flexible red, green, blue (RGB) LED strip displays UV radiation intensity as values and color codes. In addition to indicating the intensity of UV radiation in real-time through changing colors, the flexible LED also produces a flashing light when the user is in distress and needs assistance to help emergency responders locate him/her. The system also uses Bluno Beetle, the integrated BLE processor, a UV sensor, and a 3.7 V lithium-ion battery (Fig. 9).

Of the six systems designed, the EC and FA systems need to be connected to a smartphone to function, reducing its power requirement by dispensing with installing a separate global positioning system (GPS) in the wearable system, thereby reducing its power requirement. When the user requests emergency assistance through a call or a text, family members or responders can locate the wearer by tracking the smartphone using its built-in GPS. The smartphone offers other potential uses to provide added functionality. For example, when used together with the TH system, the smartphone can create and store statistical data from the sensor's surrounding temperature data to check this information when planning future trips to the same site. Based on this information, the user can decide whether to bring an extra external battery to extend the heating function or other equipment. With the UV monitoring system, the smartphone's screen provides a more user-friendly graphical user interface (GUI) than the compact built-in screen of the UV module, as the larger display makes information easier to read.

Therefore, the source codes controlling each system reflect the Bluetooth-based compatibility between the wearable system and the smartphone. There was no separate source

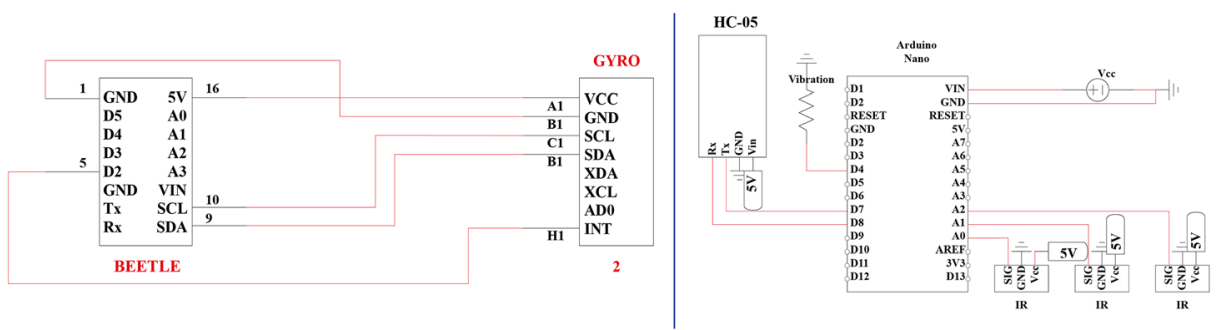

Fig. 8 Schematic diagram of the fall detection and automatic emergency calling (FA) systems: accelero-gyrosensing circuit (left) and distance measurement sensor (DMS) circuit (right) 


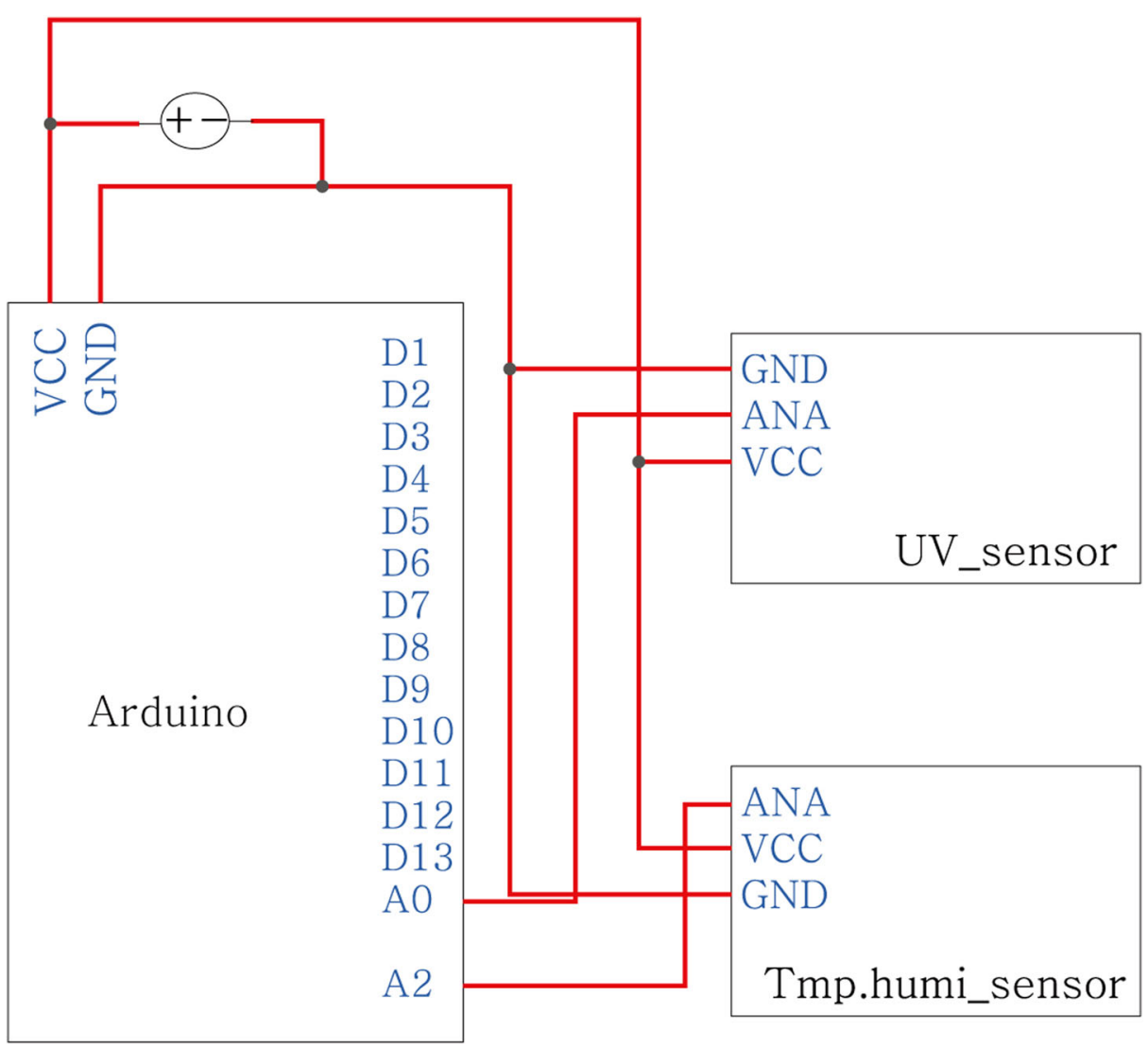

Fig. 9 Schematic diagram of the ultraviolet (UV) sensor's circuit

code for the BH function, as the integrated board's firmware controls this function. However, as the HM, TH, and UV systems continuously transmit data such as heart rate information and information about the surrounding environment, a signal transmission schedule was set to send sensor values twice every second. For the EC and FA functions designed to activate only under certain circumstances, a signal transmission rule was established so that an inactive signal is transmitted normally. An active signal is transmitted when an activation signal is received. There is an increased potential for errors because five of the six systems wirelessly transmit data to a single smartphone application via Bluetooth. The source codes about sensor values are preceded by each function's initial letter and end with a period to minimize any confusion between signals sent by different functional components of the wearable system. In addition, the source codes in each function were uploaded to Github. Here we attach the links of each code for the functions stated below in Table 5 .

Based on the completed circuitry designs, the system modules were developed with the housings built into the garment platform, and a test printing was performed with the mockup fitting. The system module housing designs focused on the 3D rendering of slanted lines and curves for seamless integration into their respective designated sites in the garment platform to not disrupt its aesthetic lines (Fig. 10). 
Table 5 Github links of each functional system for the garment platform and the smartphone application

\begin{tabular}{lll}
\hline Type & Function & Links \\
\hline Wearable system & HM & https://github.com/HyunseungLee-CRC/HyunseungLee/ \\
commit/d11c5060a08f000156aacedcac2f6e8f6a1c7b51 \\
hH
\end{tabular}

As indicated in Fig. 7, for easy removal and reattachment from and to the garment platform, a $2 \mathrm{~cm}$-wide base plate for Velcro tape was placed on each module housing. Small holes, $2 \mathrm{~mm}$ in width, were punched into the base plate at regular intervals $(4 \mathrm{~mm})$, and the Velcro tape was securely sewn onto it so that it will not loosen or shift positions even after frequent peeling and sticking. The modular system ensures the wearability and washability of the garment platform and the ease of maintenance.

Based on the circuit designs, the system modules were developed together with the housings installed in the garment platform, and a test printing ensured the adequacy of the 3D models. Errors in the design of the inner space receiving the system components and the sizing of the base plates were corrected before printing the final 3D model using the Cubicon single plus printer, an FDM-type printer, and ABS filament. The housings' surfaces were smoothened with putty and sanded, followed by compounding and coloring (Fig. 11) to ensure that the module housings do not disrupt the prototype's aesthetics.

Special attention was given to the placement of the housing circuitries to maintain the system modules' durability. Placing the system components as close as possible to one another kept using wires to a minimum. System mockups were then created to test-install them inside the 3D-printed module housings. Moreover, to allow the user to shut off the systems when they are not used to prolong battery life, a power control switch was added to all system modules, the GND circuit connecting the battery, and the processor. Furthermore, the 5-pin micro connector, an easy-to-use connector widely used for conveniently charging mobile device batteries, allows the use of any commercially available external battery pack for continued use during extended outdoor activities (Fig. 12).

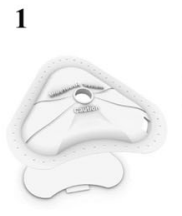

(1) Bluetooth hands-free module housing
2

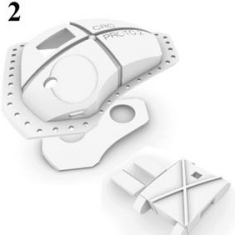

(2) Heart rate monitoring \& emergency call module housing
3

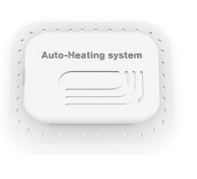

(3) Temperature-reactive heating module housing
4

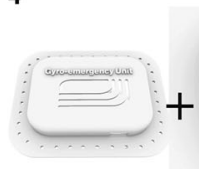

(4) Fall detection \& auto-emergency call module housings (gyro, left / DMS, right)
5

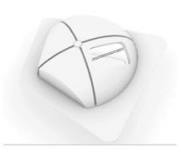

(5) UV monitoring module housing

Fig. 10 3D models of each functional system module housing 


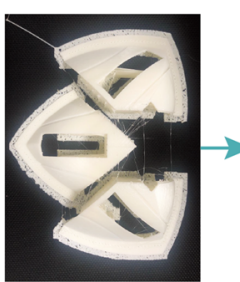

Step 1.

3D-printed

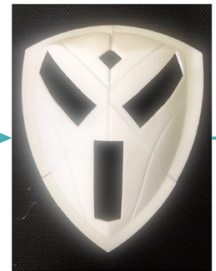

Step 2. assembled

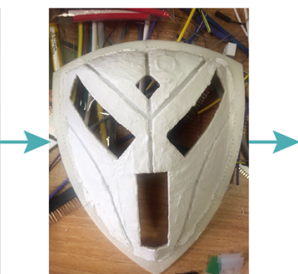

Step 3. putty coating

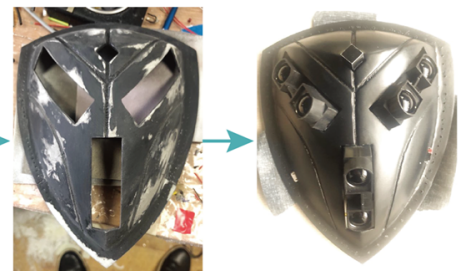

Step 4. sanding Step 5. coloring and compounding

Fig. 11 Sample images of each system module housing development

Devising a method allowing easy removal and reattachment of the modules was necessary for the garment platform. First, holes were punched in the garment platform in shapes and sizes that precisely match each system module's outlines. A Velcro-based assembly mechanism was created by placing anchors on the outer shell's underside, along the holes' edges, and on a hidden base plate for Velcro tape on the module housings' inner side (Fig. 13).

Development of smartphone application for expansive functionality A dedicated smartphone application was developed to support the extended functionality and control system processes when connected to a smartphone. The application is designed on the Android platform, as Android is an open-source-based system compared to the closed source iOS $[1,15]$. The extended functionality provided by the wearable system through the dedicated smartphone application is as follows. First, the HM function, in addition to monitoring heart rates, also collects and stores related data and provides them to the user as statistics. Second, upon receiving emergency call signals, the EC function makes calls and sends texts to emergency responders and the user's chosen contacts listed on the phone. After sending the calls and texts, the smartphone screen displays images with a flashing light to guide the first responders to the user's location. Third, the TH function monitors the current temperature and gathers and stores temperature data to provide the user with statistical information. Fourth, the DMS installed on the back of the garment platform detects objects approaching from behind in three different directions, displayed in real-time as soon as they enter the detectable range in the form of a graph to alert the user visually. Fifth and last, the UV function monitors the intensity of UV radiation at the current point in time.

The application developed to support said functionalities is optimized for Android API 23 (Android 6.0) and above. Bluetooth provides communication between the wearable and the application through five Bluetooth modules controlling the five functions, some of which are Bluetooth Classic and others are BLE. Tiduino-based circuits use Bluetooth Classic and BLE

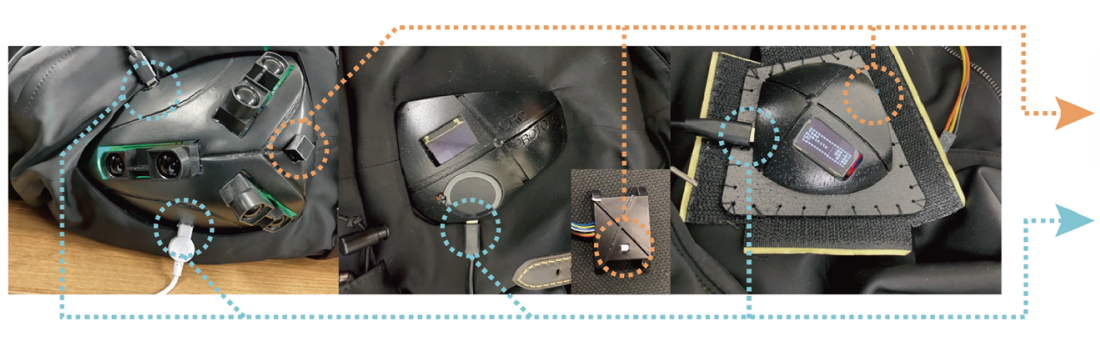

Main power control switch

5-pin power charge socket

Fig. 12 Application of the main power control switch and micro 5-pin charger 


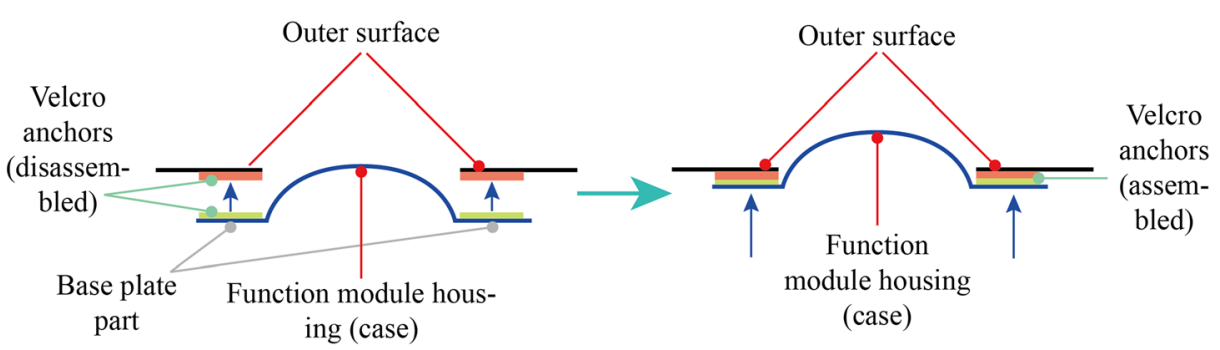

Fig. 13 The assembling-disassembling method between the platform and modules

for Bluno Beetle. The gateway dispenses with a Bluetooth module selection screen by having separate communications managers automatically find the right Bluetooth module when each system component connects to the application (Fig. 14).

The HM, EC, and TH system connection, which uses Bluetooth Classic, is ensured through BluetoothClassicManager [6]. While Bluetooth Classic and BLE are structurally distinct, communication occurs through the same three steps: device search $\rightarrow$ connection $\rightarrow$ retrieval of data. The FA and UV systems, which use BLE, look for a BLE module nearby based on the list of preassigned BLE addresses and attempt to establish a connection with a discovered module $[6,21,22]$. When the connection is successful, the screen displays the corresponding wearable function. Although Android has a built-in SQLite (open-source DBMS) and mainly uses the SQLite database, this study utilized the Realm database, which is more intuitive to use and has faster reading and updating rates $[1,6,17,41,44]$. The application developed based on

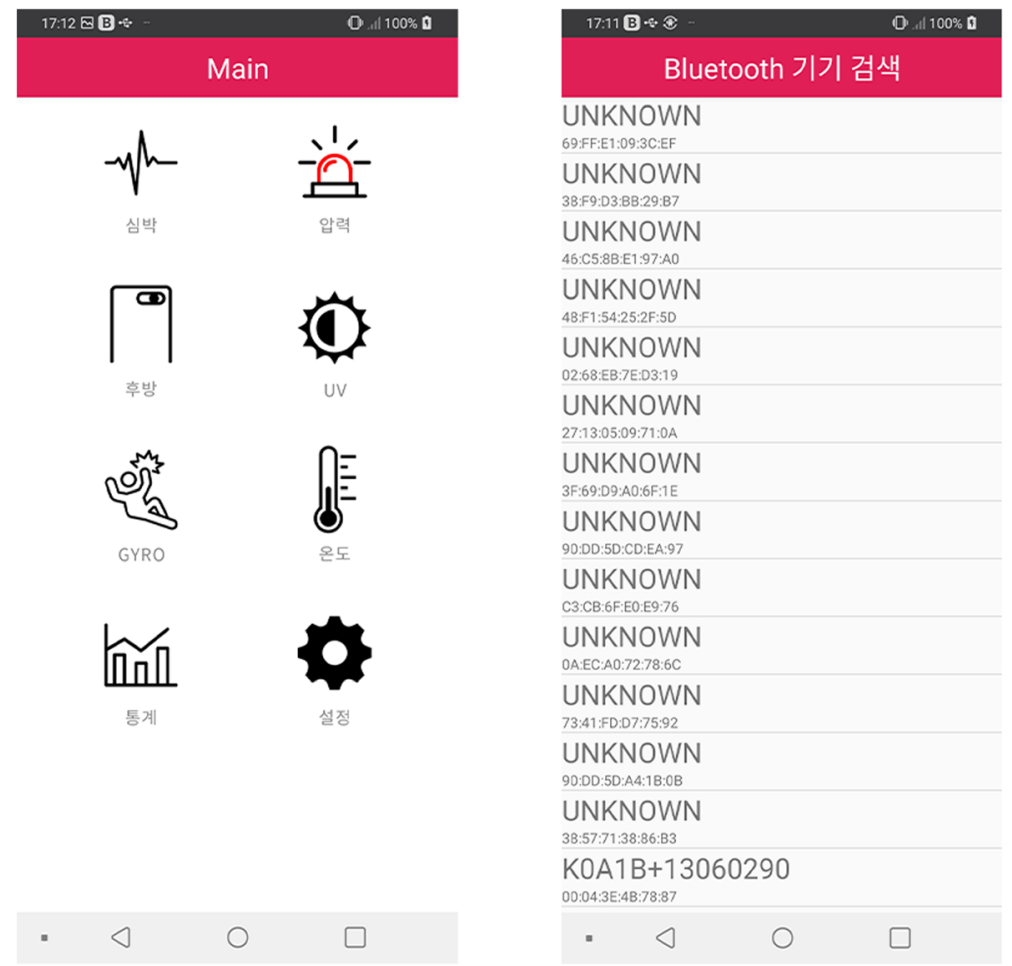

Fig. 14 Graphical user interface (GUI) images of function selection (left) and Bluetooth connection (right) 


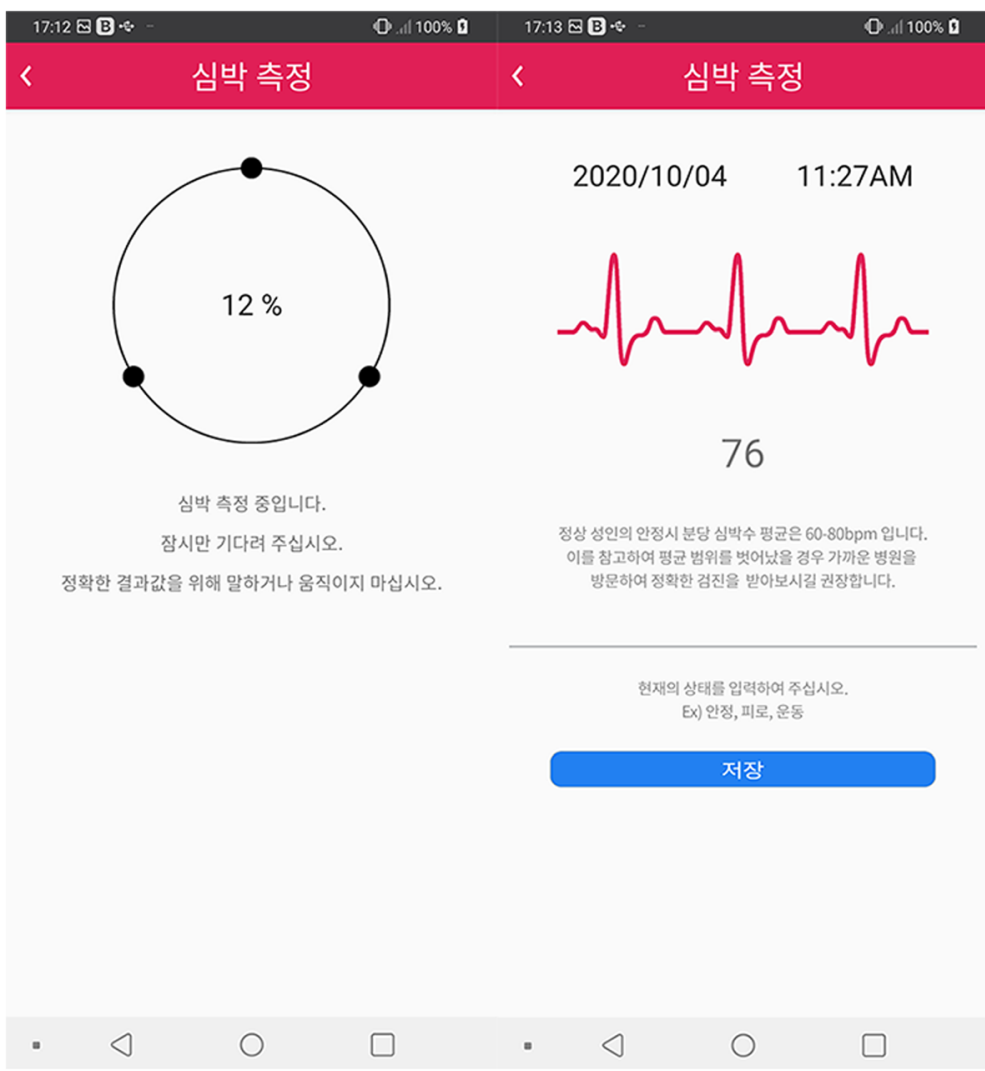

Fig. 15 The heart rate measuring screen (left) and the screen displaying the measured heart rate value (right)

this logical structure has the following operating mechanism. The HM function measures the user's heart rate every $45 \mathrm{~s}$, and stores the data in the database. The application then displays the average heart rate based on stored data (Fig. 15).

The EC function, activated by the user through the input of pressure signals, makes calls and sends texts to alert emergency responders and pre-selected contact persons. The phone screen displays a simple flashing light animation to assure the user that the application functions correctly and guides the responders to his/her location (Fig. 16). Meanwhile, the $\mathrm{TH}$ function provides temperature information from the garment-based system using an intuitive display based on three different background images corresponding to three temperature levels. The temperature values are continuously obtained from the wearable system and stored in the database (Fig. 17). The UV function displays the intensity of UV radiation as an 11-point scale index. Index values and the corresponding impact on the human body are colorcoded and indicated in text form (Fig. 18).

The FA function is triggered automatically when the gyro-sensing and DMS systems detect unusual movements or changes in the body's location, suggesting a fall, and transmits an activation signal. Calls and texts alert emergency responders and the user's designated contact persons. Like the EC function, the FA function also displays the flashing lights animation on the phone screen to guide approaching persons to the user's location (Fig. 19). The derivative 


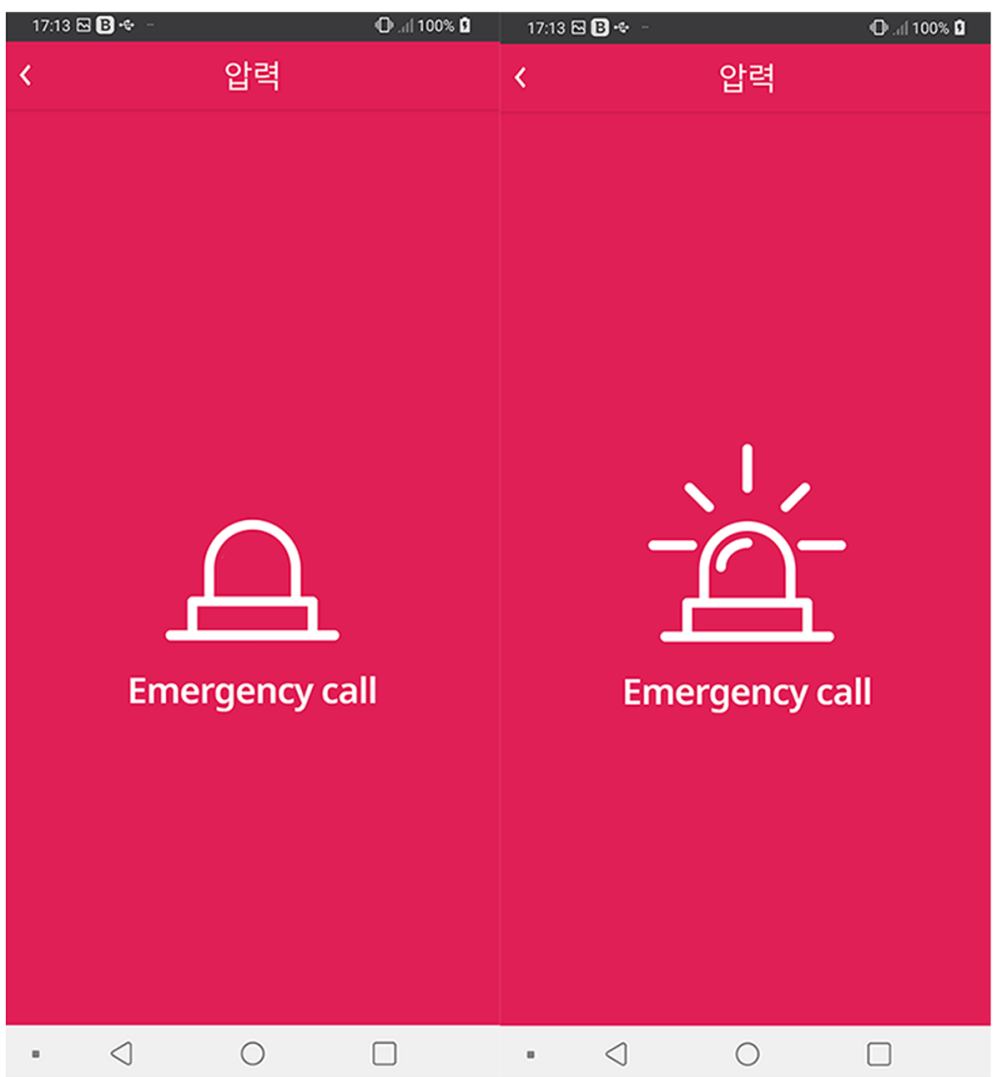

Fig. 16 The normal status screen (left) and the emergency alerting screen (right) of EC function

function enabled by the DMS system, sensing objects approaching from behind, displays the real-time distance of an object in three different directions (center rear, left rear, and right rear) in the form of a graph (Fig. 20).

The statistics page lets users check their heart rate and temperature data, measured by the HM and TH systems. This page displays both daily and monthly values as a graph by retrieving data from the Realm database. The heart rate is the real-time value, current as of the display, while the temperature is a 20 -s average value calculated from the stored values transmitted by the sensor twice per second. The user can select emergency contact persons in the Settings menu to notify when the EC and FA functions are activated (Figs. 21, 22 and 23). Meanwhile, the source code of this smartphone application can be found on GitHub (Table 6).

\subsection{Prototype usability testing results}

In this study's R \& D stage, two converging research branches were considered: apparel design and engineering technologies (electronic and software). The first branch focused on the technical investigation of the design and construction of the platform's form, internal and external structural details, and material application. This step saw the installation of rigid 
Fig. 17 The temperature monitoring screen
$17: 20 \mathrm{~N} \cdot \mathrm{B}$

(1). $.1100 \%$ B

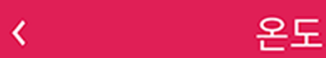

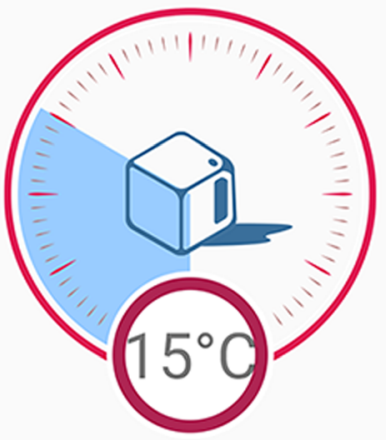

system components (circuits and housings), consisting of electronic circuit components and module housings, in the platform.

The second branch focused on investigating and developing condensed circuits with durable and aesthetically pleasing housings, where the system modules would be placed in a flexible platform. Based on the two research branches, the study aims to bridge the gap between fashion and engineering by integrating wearable sensing and HAR functionalities into clothing.

The final stage of R \& D saw the completion of the multifunctional smart outdoor jacket prototype by installing the wearable system modules into the garment platform (Fig. 24). The developed prototype and the locations of each wearable system are stated in Fig. 18. The developed prototype's weight with and without the wearable system modules and each device's weight, including batteries, were indicated in Table 6, affecting wearability and the users' activities.

This study's prototype aims to provide multiple functions that ensure the user's health and safety. Similarities functions were observed between this study's prototype and the previously 
Fig. 18 The screen displaying the ultraviolet level

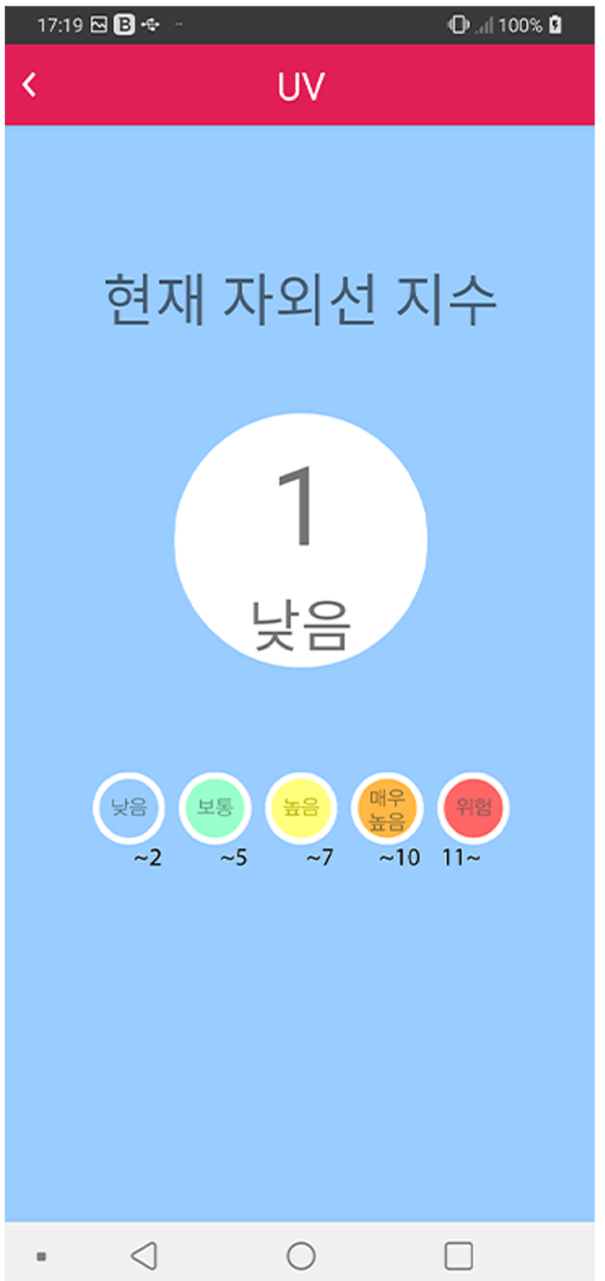

mentioned study prototypes. Although Coron's Life Tech Jacket and Ororo's Softshell jacket provide electronically induced heating functions similar to this study prototype's TH function $[3,4,46]$, there are two key differences in the power supply and operation control. The softshell jacket's heating function is activated with a 7.4 V power supply, while the Life Tech Jacket and softshell jacket's functions were manually activated by the user. However, this study prototype's TH function was designed to adapt a $5 \mathrm{~V}$ power supply commonly used in mobile devices, and the prototype's system is automatically activated using a temperature sensor.

The prototype in Park et al.'s study was designed to monitor a user's heartbeat in real-time while performing outdoor activities [40]. Despite its similarities with this study's HM function, some changes were made to address the washability of the clothing platform and the systems' sensors. Park et al. addressed the washability of the shirt by applying a dry ECG senor with conductive fabric electrode patches directly attached to the user's skin, to be replaced when the prototype needs to be washed or when the patch is replaced. For this study's HM system, a PPG sensor (optical sensing type) was used to measure the user's heart rate; the circuit was installed 


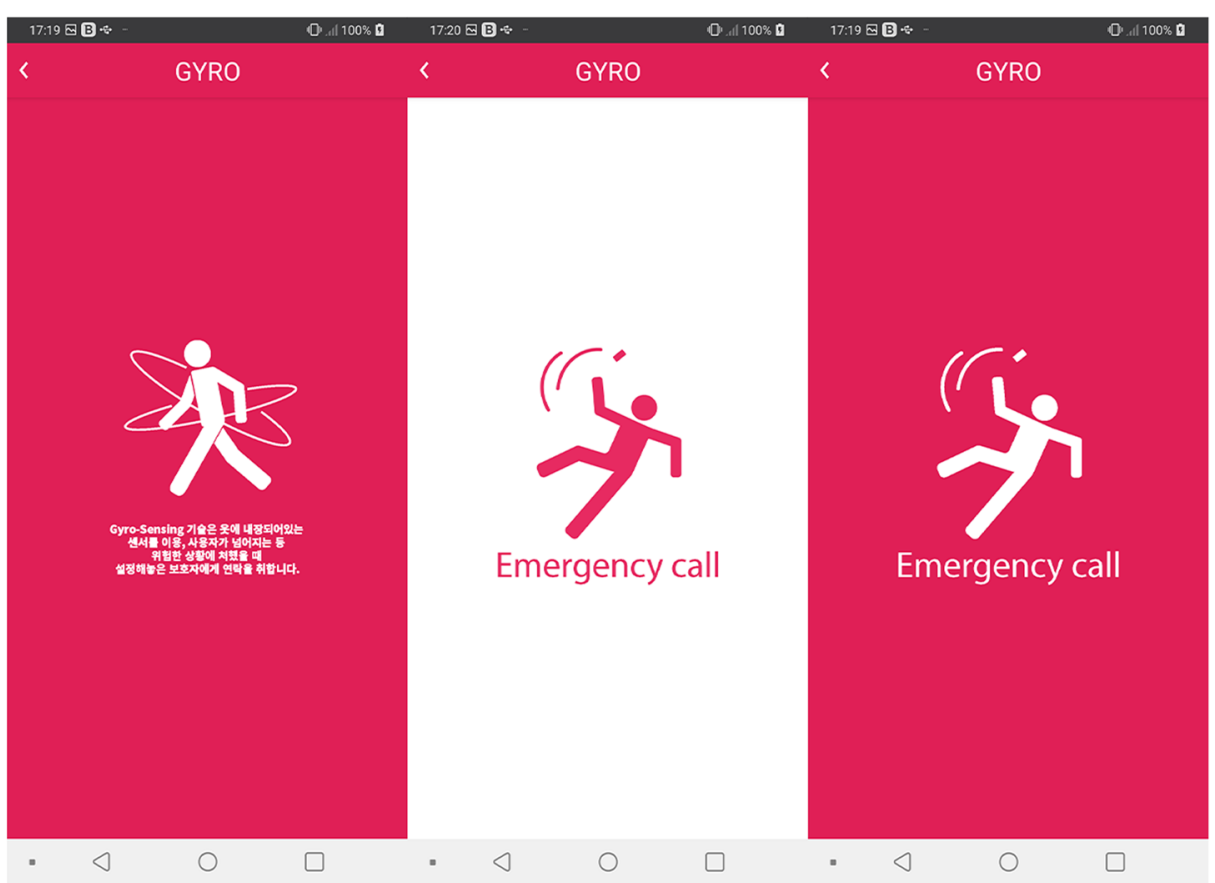

Fig. 19 The default screen (left) and animation displayed during emergency alerting (middle, right) of FA function

in an independently modularized housing easily detachable from the garment platform. As a result, electrode replacement and the garment platform washing were already considered.

Li et al.'s system tracks its user's walking speed and eye movements through a smartphone's built-in gravity sensor, accelerometer, and forward-facing camera [28]. In urban environments, tracking walking speed and eye movements can be efficient. However, doing so in outdoor environments would be difficult and dangerous because of uneven surfaces and slopes in wild terrain. Changes in incline angles were crucial factors that affected safety in mountainous areas. Therefore, a six-axis gyro accelerator sensor was used to simultaneously measure the acceleration and angle changes during fall detection rather than an image processing camera system, and the DMS system was used during fall detection on slopes.

Meanwhile, Li et al.'s Android application framework was designed to detect jumping motions based on a peak-valley-peak pattern identified by acceleration changes on the $\mathrm{x}$ - and $y$-axes revolving around a z-axis [29]. However, this study's FA system was designed to detect sudden and extreme vertical acceleration changes on the z-axis and various changes along the $\mathrm{x}-, \mathrm{y}-$, and $\mathrm{z}$-axes to focus on fall detection in uneven and unpredictable outdoor environments. Watson et al.'s previous study focused on elbow motion tracking accuracy using an electromagnet-based sensing system that can be mounted on the user's body [53]. As this study's FA function was designed for fall detection in diverse outdoor environments, a six-axis gyro accelerator sensor less affected by uncontrollable external stimuli was utilized, and DMSs were applied to the FA system to circumvent the accelero-gyro-sensing system's limitations in certain geological conditions.

The prototypes of previous studies focused on the realization of one specific platform function. In comparison, this study aimed to apply multiple outdoor activity functions into one 
Fig. 20 The screen showing an approaching object detected from the user's rear
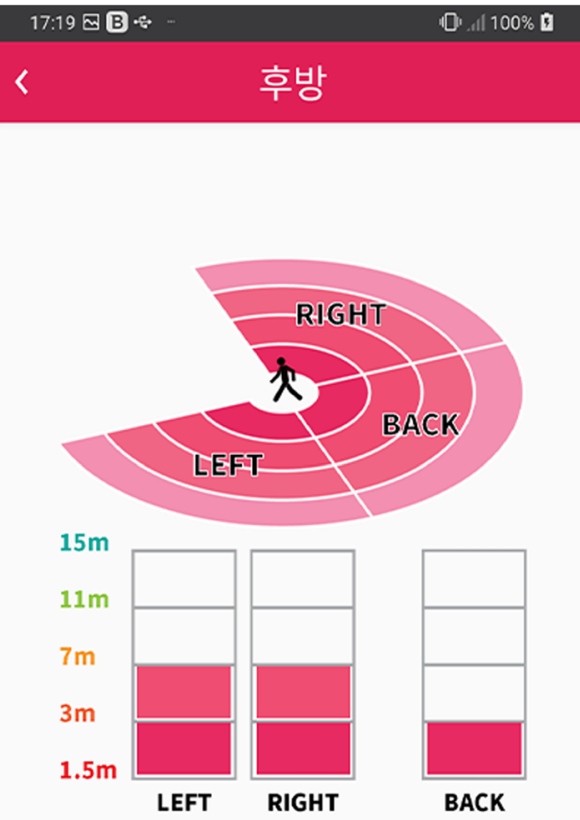

Rear-Detection 기술은 사용자의 좌, 우, 후방으로부터 다가오는 위험 인자를 인식, 출력하여 사용자가 대비할 수 있게 합니다. 약 $1.5 \mathrm{~m}$ 부터 최대 $15 \mathrm{~m}$ 까지 인식합니다.
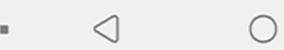

clothing platform. Tests were conducted with three testers in an outdoor environment to confirm the usability of this study's prototype.

The prototype was tested twice for wearability and ease of movement in Bukhan Mountain National Park, South Korea. Three evaluators, labeled as A, B, and C, with different heights, weights, and experiences, were recruited to the study (Table 7). The first test was conducted with evaluator $\mathrm{A}$, while the second test was performed by evaluators $\mathrm{B}$ and $\mathrm{C}$ in the same environment (Fig. 25).

The testers wore the prototype in the test area and confirmed the ease of mobility in each body part (arms, torso, legs, and joints). While climbing and moving, the testers experimented with the prototype's operability and the accuracy of the data obtained by each of the platform's systems (Fig. 19).

The specific tasks of the system operation in the experimental processes are as follows. First, the BH function was tested to confirm its compatibility with the tester's smartphone and phone call quality in the environment. The experiment confirmed the effective operation of the BH system. 
Fig. 21 Heart rate and temperature selection screen
$17: 20$ @ $\div$

[D. $100 \%$

$<$

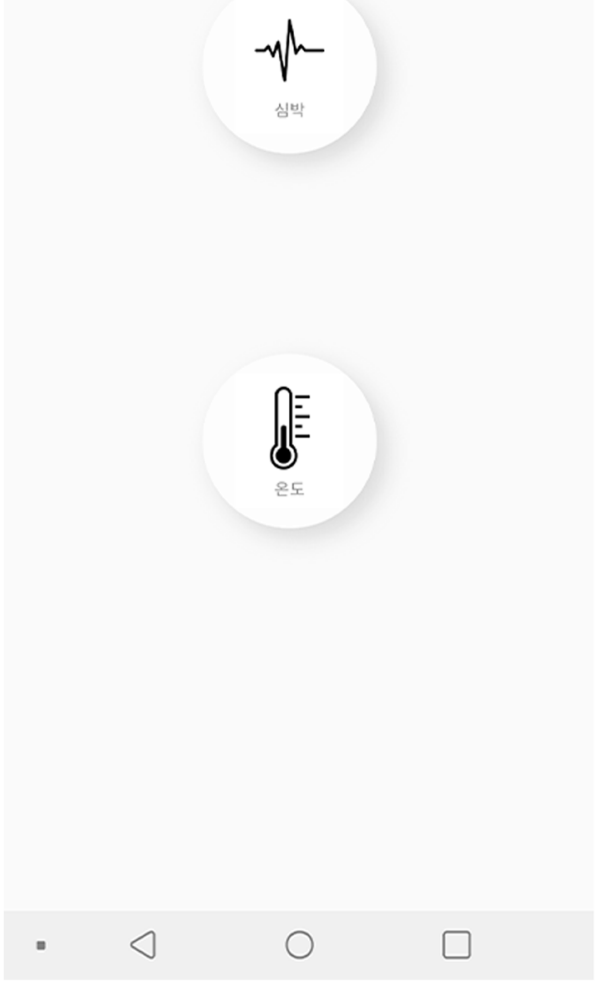

Second, the FA function experiments were performed in two ways. The garment was initially placed on a mannequin and thrown down the side of the mountain to determine if the emergency call and message sent from tester A's phone were received by a researcher standing at the mountain's base. Afterward, the testers wore the prototype to determine whether the FA system reacted to the testers' motions and changes in their bodies' angles. Based on the results, the FA system effectively operated as the system did not react to the configured actions.

Third, the DMS system testing was conducted when a researcher approached the tester's rear from three directions (directly behind, left, and right), and the testers monitored the researcher's direction and distance. Afterward, the testers experimented with the DMS system's compatibility with the FA system by lying on the ground near rocks and collapsed trees to determine if the system sent an assistive signal to the FA system's gyro module when the distance between DMS and the ground or objects was $15 \mathrm{~cm}$ to $30 \mathrm{~cm}$. The results confirmed that the DMS system operated effectively in both tests. 


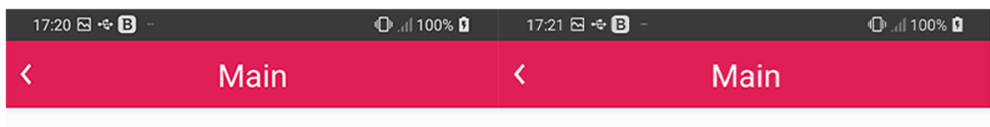

\section{일간}

월간

일간

욀간

$2020 / 9 / 28$
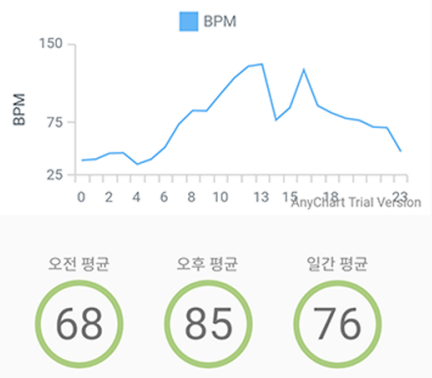

$2020 / 9 / 28$

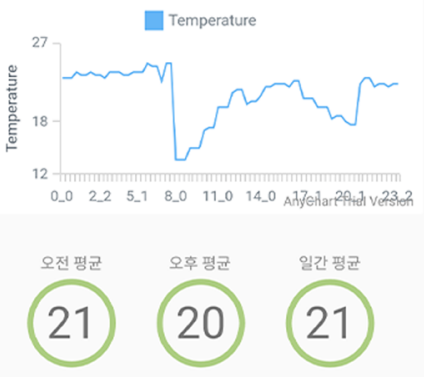

Fig. 22 Heart rate data (left) and temperature data (right) statistics screen

Fourth, in the TH function tests, the recorded temperature's accuracy was evaluated by comparing it with the National Weather Service's official temperature data. The testers also tested the automatic heating function using a thermometer placed in an internal pocket when the external temperature was below $13{ }^{\circ} \mathrm{C}$. The tests confirmed the automatic heating function's operability before reconfiguring the platform to test heating sheets' operability. This second test also confirmed the operability of the TH system.

Fifth, the manual EC function's operability integrated into the HM module was tested to determine if the emergency call and message were sent to the researcher's smartphone when the testers placed their hands on the HM module's touch sensor on their left arm. This test confirmed the EC's function.

Sixth, the HM function's operability and the measured data's accuracy were tested by comparing them with heart rate data measured by commercially sold smartwatches (Apple and Samsung). The testers wore the smartwatches and the prototype simultaneously and measured their heart rate while performing various activities. After the climbing activities were finished, each tester's heart rate data, measured by each device, were examined to evaluate the measured data's accuracy. The results confirmed the similarity of the measured values. However, small differences between the measured values were noticeable because the HM system was designed to perform similarly to an electrocardiogram (ECG). 
Fig. 23 Settings menu screen for configuring emergency call phone numbers
$17: 21$ ब

(10.) $1100 \%$

$<$

설정

Haptic-Pressure Call

112에 신고

전화번호 선든

112

Gyro-sensing Call

119 에 신고

전화번호 선텩

119

Seventh, testing for damage caused by collisions with the modules or trees was also performed, but none were observed. The Velcro joint structures between the platform and the housings did not show any damage because they were anchored toward the garment's inner surface with thread and an epoxy resin adhesive. After each experiment, the testers were interviewed and surveyed, and battery life in each wearable system module was determined. The wearable system was

Table 6 The weight of the prototype's components and total weight (in g)

\begin{tabular}{|c|c|c|c|c|c|c|c|c|}
\hline \multirow[t]{2}{*}{ Category } & \multirow{2}{*}{$\begin{array}{l}\text { Garment platform } \\
\text { (without devices) }\end{array}$} & \multirow{2}{*}{$\begin{array}{l}\mathrm{BH} \\
\text { module }\end{array}$} & \multirow{2}{*}{$\begin{array}{l}\text { HM module } \\
\text { including } \\
\text { sensor } \\
\text { module part }\end{array}$} & \multirow{2}{*}{$\begin{array}{l}\mathrm{TH} \\
\text { module }\end{array}$} & \multicolumn{2}{|c|}{ FA system modules } & \multirow{2}{*}{$\begin{array}{l}\text { UV } \\
\text { module }\end{array}$} & \multirow[t]{2}{*}{ Total } \\
\hline & & & & & Accelero-gyro & DMS & & \\
\hline Weight & $1486 \mathrm{~g}$ & $39 \mathrm{~g}$ & $110 \mathrm{~g}$ & $490 \mathrm{~g}$ & $52 \mathrm{~g}$ & $160 \mathrm{~g}$ & $40 \mathrm{~g}$ & $2277 \mathrm{~g}$ \\
\hline
\end{tabular}


placed on a mannequin and switched on in a mountainous environment to have each internal system react with external stimuli until each system's batteries gave out. The test was then continued while descending the mountain until the testers reach the base of the mountain. Based on the results, each system could stay active for four hours $(3 \mathrm{~h}$ were spent during active evaluation), and each system's battery life is tabulated in Table 8.

After each test, except the battery life test, the testers filled a questionnaire composed of a five-point Likert scale (Table 9), and each tester's answer was tabulated (Table 10).

As seen in Table 10, the three testers gave positive feedback on the garment platform's wearability, operability, and ease of motion because the scores given were over 4.0 in the individual categories and 4.4 and 4.1 on average. After answering the questionnaire, the testers were interviewed to obtain specific comments about the prototype. The prototype's performance was based on five criteria: design and functionality; the visual balance between the garment platform and the system modules; obstructiveness of the system modules; ease of use; and the visibility and usability of the smartphone app's GUI.

The specific results based on the testers' comments were as follows. First, the garment platform's design and functionality were suitable for mountaineering activities to protect the user's body while performing outdoor activities. Second, the prototype's exterior was well-organized, and the differences in materials between the fabric and the ABS polymer modules are distinguishable. Third, the oversized garment platform did not restrict movement despite having each functional module distributed across the platform. Fourth, the various input-output interfaces were easy to use, and all system components worked as expected. However, tester A commented that reading the UV values on the UV system's built-in screen was difficult because of the small font, which was noted as a point for improvement. Fifth and last, the images and text used in the app's GUI were intuitive, and all functions were easy to use. There were no issues while monitoring the sensors' functions, accessing statistics, making emergency calls, and sending texts.

Meanwhile, one tester noted that the 45-s processing time of the HM system, which is the time taken to eliminate noise from heart rate data and calculate the average value, was considered too long, even though the application checks this information while the user is on the move. This issue was noted as another point for improvement. Additionally, after measuring the prototype's battery life, additional interviews with the three testers were conducted to evaluate battery performance. During the interview, the testers determined that the battery lives of the BH system, DMS module, and the UV system were insufficient and should be upgraded for professionals or military personnel who perform extreme outdoor activities over $5 \mathrm{~h}$. However, the testers also provided positive assessments for the battery life as each system would be suitable for the general public because the batteries could be easily replaced or recharged using a 5-pin micro connector regardless of the environment.

Based on the results of each experiment, and aside from issues related to the font size of the UV module, the app's processing time for HM data and the battery life of the wearable systems, the prototype, its systems, and the dedicated app, performed satisfactorily for functionality and usability. The garment platform is highly wearable, and the wearable system and the dedicated app functioned well and were easy to use. This study confirms that the study's goal was accomplished.

\section{Conclusion}

Clothing has the potential to diversify wearable sensing and HAR functions. Based on this premise, the study investigated the convergence of knowledge and techniques in apparel 

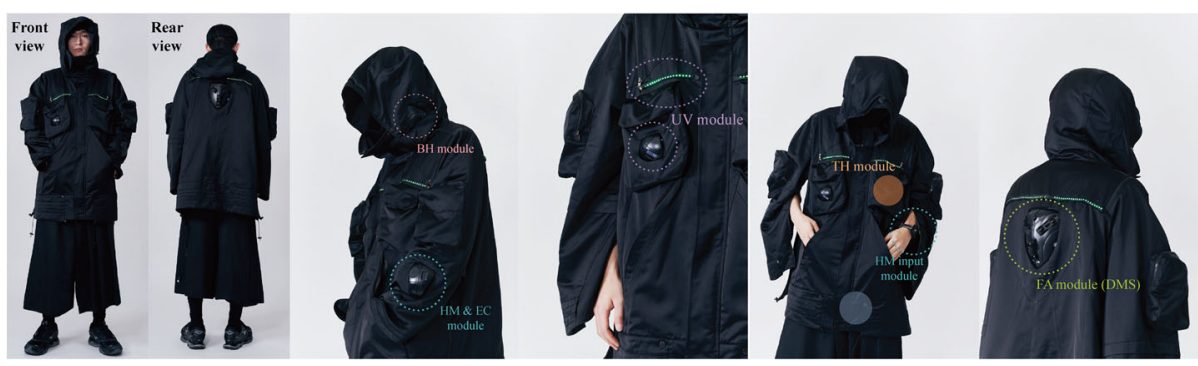

Fig. 24 The prototype worn on a male model and locations of the equipped wearable devices

design and engineering to achieve wearable sensing and HAR system functionality in a clothing platform that monitors users' health and their situation in outdoor environments. The resulting prototype factors in the ranges of movement of each body part, the electronic components' durability, and a suitable clothing platform during its construction to create a wearable system that interacts with the user's body and an accompanying smartphone app.

As a result of this study, the smart outdoor jacket prototype and a smartphone application linked with the prototype's wearable system to provide it with extended functionality were developed. The system provides six functions to assist users in unpredictable outdoor environments, monitor their health status, and efficiently respond to emergencies: (1) Bluetooth handsfree calling, (2) heart rate monitoring, (3) emergency calls, (4) temperature-reactive heating, (5) fall detection and automatic emergency calls, and (6) UV monitoring. The evaluators tested the prototype's wearability and usability, the systems, and the smartphone application through the climbing activity. The test found no significant issues except two small points for improvement,

Table 7 The physical condition of each evaluator

\begin{tabular}{lllll}
\hline Tester & Height $(\mathrm{cm})$ & Weight $(\mathrm{kg})$ & Outdoor activity expertise & Age \\
\hline A & 182 & 75 & Camping, tracking & 30 \\
B & 178 & 85 & Tracking, rafting, camping & 28 \\
C & 186 & 69 & Tracking, camping, winter sports & 26 \\
\hline
\end{tabular}

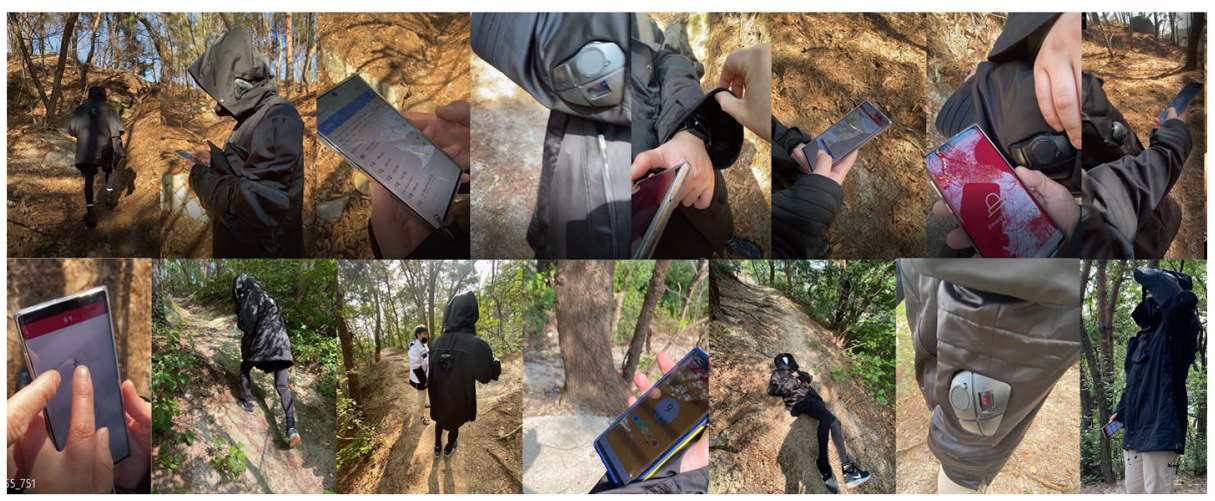

Fig. 25 The photos indicating the situations of the experiments in the outdoor environment by the three evaluators 
Table 8 Approximate battery life of each wearable system during the usability experiments

\begin{tabular}{lllllll}
\hline System & BH module & $\begin{array}{l}\text { HM module including } \\
\text { sensor module }\end{array}$ & TH module & FA system modules & UV module \\
\cline { 5 - 6 } & & & Accelero-gyro & DMS & \\
\hline
\end{tabular}

which are the font size used for the display of UV values on the built-in screen of the UV module and the processing time of HM data. The overall prototype, including the garment platform, wearable system, and smartphone application, performed as expected.

This study aims to develop wearable sensing and wearable HAR systems to provide consistent and proximate health care and emergency treatment functionality through vital sign monitoring and activity recognition using clothes to surpass the limited accessibility of existing medical care systems. By transferring the operation of health-focused sensing and HAR functions from indoor spaces to clothes worn on the human body, the study also hoped to bridge the potential role of fashion and engineering sciences and expand healthcare and safety.

This study could be used as a basis for developing wearable systems with extended functionalities. First, the prototype applied the concepts of wearable sensing, context-aware computing, and wearable interfaces, which led to creating functions that recognize the user's vital signs, movements and change the body's position. Future research can develop a wearable HAR system with GPS systems for childcare purposes, including tracking their locations and monitoring their health and physical activities.

Second, gyro sensing and distance sensing technologies used to the prototype's FA function and the autonomous operation could improve detection ranges and provide alternative control interfaces that do not rely on the user's visual or auditory input. This improvement could develop a wearable system with direction-based sensors to assist auditory or visually impaired people in any environment. In addition, developments in wearable sensing systems can improve the lives of physically challenged people as they perform their daily activities.

Table 9 Questionnaire of the evaluation for the evaluators (translated in English)

1. Garment Platform
2. Functionality (wearable system/smartphone application)

1-1. The aesthetic-visual balance between the garment platform and the module housings.

1 (Bad) $2 \quad 3$ (Neutral) $4 \quad 5$ (Good)

$1-2$. The usability of functional details, wearability, and activity of body movement during the climbing activity.

1 (Bad) $2 \quad 3$ (Neutral) $4 \quad 5$ (Good)

$1-3$. Did you feel that the system modules (wearable system) disturbed body movements during climbing situations?

$\begin{array}{lllll}1 \text { (Yes) } & 2 & 3 \text { (Neutral) } & 4 & 5 \text { (No) }\end{array}$

$1-4$. How was the prototype's total weight, including the garment and the suitability for intense outdoor (climbing) activities?

\begin{tabular}{|c|c|c|}
\hline 1 (Bad) & 2 & \\
\hline
\end{tabular}

\section{2-1. The operating interface (power switch and} input interface) of the wearable system (?)

1 (No) 23 (Neutral) $4 \quad 5$ (Yes)

2-2. Did you easily check the output interface (screens) of the wearable system?

1 (No) 23 (Neutral) 45 (Yes)

$2-3$. Did you easily perceive and handle the GUI of the smartphone application?

1 (No) 23 (Neutral) $4 \quad 5$ (Yes)

2-4. Was the smartphone application effectively operated during mountaineering activities? 
Table 10 The result of the assessment with the questionnaire by each tester

\begin{tabular}{|c|c|c|c|c|}
\hline \multirow{2}{*}{$\begin{array}{l}\text { Tester } \\
\text { A }(30 \text { years old })\end{array}$} & \multicolumn{2}{|c|}{$\begin{array}{l}\text { Results of the assessment by the five-points } \\
\text { criterion about the garment platform in each } \\
\text { question }\end{array}$} & \multicolumn{2}{|c|}{$\begin{array}{l}\text { Results of the assessment by the five-points } \\
\text { criterion about functionality in each ques- } \\
\text { tion }\end{array}$} \\
\hline & $1-1$ & 5 & $2-1$ & 4 \\
\hline & $1-2$ & 5 & $2-2$ & 3 \\
\hline & $1-3$ & 4 & $2-3$ & 4 \\
\hline & $1-4$ & 4 & $2-4$ & 4 \\
\hline & Average & 4.5 & Average & 3.5 \\
\hline \multirow[t]{5}{*}{ B (28 year } & $1-1$ & 4 & $2-1$ & 5 \\
\hline & $1-2$ & 5 & $2-2$ & 4 \\
\hline & $1-3$ & 5 & $2-3$ & 5 \\
\hline & $1-4$ & 5 & $2-4$ & 4 \\
\hline & Average & 4.75 & Average & 4.5 \\
\hline \multirow[t]{5}{*}{ C (26 years old $)$} & $1-1$ & 4 & $2-1$ & 4 \\
\hline & $1-2$ & 4 & $2-2$ & 4 \\
\hline & $1-3$ & 4 & $2-3$ & 5 \\
\hline & $1-4$ & 4 & $2-4$ & 4 \\
\hline & Average & 4.0 & Average & 4.25 \\
\hline Total average & 4.4 & & 4.1 & \\
\hline
\end{tabular}

Acknowledgments The authors would like to acknowledge Eunjung Lee, Professor, Dept. of Fashion Design, Kookmin University, for her assistance and support during the study.

Authors' contributions Conceptualization: Hyunseung Lee; Methodology: Hyunseung Lee; Formal analysis and investigation: Hyunseung Lee, Kyungsoon Baek; Writing - original draft preparation: Hyunseung Lee, Kyungsoon Baek; Writing - review and editing: Hyunseung Lee; Resources: Hyunseung Lee; Supervision: Hyunseung Lee.

All authors read and approved the final manuscript.

Funding This work was supported by the National Research Foundation of Korea (NRF) Grant funded by the Korean Government (MSIP) (Grant No. 2015R1A5A7037615).

Data availability Not applicable.

Code availability The library codes for each of the prototype's systems are provided below, which are freely accessible.

1. The library code (AFE4403_Raw.h) for the heartbeat measurement system is available on Device Mart (https://www.devicemart.co.kr/goods/view?no=1272988\#goods_file).

2. The library code (TinyScreen) for controlling the heartbeat monitoring system is available on TinyCircuits/ TinyCircuits-TinyScreen_Lib (https://github.com/TinyCircuits/TinyCircuits-TinyScreen_Lib).

3. The codes (BluetoothLeGatt) for the smartphone application (AS) are available on android/connectivity samples/BluetoothLeGatt (https:/github.com/android/connectivity-samples/tree/master/BluetoothLeGatt).

4. The code of this study's HM system is available on GitHub (https://github.com/HyunseungLee-CRC/ HyunseungLee/commit/d11c5060a08f000156aacedcac2f6e8f6a1c7b51).

5. The code of this study's TH system is available on GitHub (https://github.com/HyunseungLee-CRC/ HyunseungLee/commit/6b0d674d1bfb127f3e8a5eae035225e0bfe66165).

6. The code of this study's acellero-gyro module (FA system) is available on GitHub (https://github.com/ HyunseungLee-CRC/HyunseungLee/commit/0a9df0a427e8d86c8caac853362b7ff511ddf78d).

7. The code of this study's DMS module in the (FA system) is available on GitHub (https://github.com/ HyunseungLee-CRC/HyunseungLee/commit/f6339ae6ff464fd1c3da90f1de939ccb1c517057).

8. The code of this study's UV system is available on GitHub (https://github.com/HyunseungLee-CRC/ HyunseungLee/commit/e46b26c2f37ff73829941d564ae0fd028f9abb6c).

9. The codes of this study's smartphone application (Android) is available on GitHub (https://github.com/ $\mathrm{kmucrc/MassCustom/commit/4e8224de42cbf29ad20a1ceb0ee87f4f535fcff4).}$ 


\section{Declarations}

Competing interests The authors declare that they have no competing interests.

Open Access This article is licensed under a Creative Commons Attribution 4.0 International License, which permits use, sharing, adaptation, distribution and reproduction in any medium or format, as long as you give appropriate credit to the original author(s) and the source, provide a link to the Creative Commons licence, and indicate if changes were made. The images or other third party material in this article are included in the article's Creative Commons licence, unless indicated otherwise in a credit line to the material. If material is not included in the article's Creative Commons licence and your intended use is not permitted by statutory regulation or exceeds the permitted use, you will need to obtain permission directly from the copyright holder. To view a copy of this licence, visit http://creativecommons.org/licenses/by/4.0/.

\section{References}

1. Android Developers (n.d.) Bluetooth overview. Android developers. https://developer.android.com/guide/ topics/connectivity/bluetooth/. Accessed 27 May 2020

2. Backe S, Ericson L, Janson S, Timpka T (2009) Rock climbing injury and associated risk factors in a general climbing population. Scand J Med Sci Sports 19(6):850-856. https://doi.org/10.1111/j.1600-0838. 2008.00851.x

3. Becker K (2018) The best heated jackets. Digital Trends. https://www.digitaltrends.com/outdoors/bestheated-jackets/. Accessed 1 Feb 2020

4. Becker K, Oswald E (2020) Conquer the cold with the best heated clothing and outdoor apparel for 2020. Digital Trends. https://www.digitaltrends.com/outdoors/best-heated-clothing/. Accessed 21 Dec 2020

5. Black S (2010) Reconciling electronics and fashion: cute Circuit's Francesca rosella and Ryan Genz in conversation with Sandy Black. Fash Pract 2(1):105-120. https://doi.org/10.2752/ 175693810X12640026716519

6. Bluetooth (n.d.) Learn about Bluetooth radio-versions. Bluetooth. https://www.bluetooth.com/learn-aboutbluetooth/bluetooth-technology/radio-versions/. Accessed 8 Feb 2020

7. Burns N, Watson N, Paterson K (2013) Risky bodies in risky spaces: disabled people's pursuit of outdoor leisure. Disability \& Society 28(8):1059-1073. https://doi.org/10.1080/09687599.2012.749180

8. Cho GS, Lee SS, Cho JY (2009) Review and reappraisal of smart clothing. Int J Hum Comput Interact 25(6):582-617. https://doi.org/10.1080/10447310902997744

9. Choi JW, Kim SC (2016) Is the smartwatch an IT product or a fashion product? A study on factors affecting the intention to use smartwatches. Comput 63:777-786. https://doi.org/10.1016/j.chb.2016.06.007

10. Costanza E, Inverso SA, Allen R, Maes P (2007) Intimate interfaces in action: assessing the usability and subtlety of EMG-based motionless gestures. In: Proceedings of the SIGCHI conference on human factors in computing systems, San Jose, CA: ACM, pp. 819-828. San Jose, California, USA

11. D'Orazio D (2012) Nike+ basketball and training sneakers track your game, push you to compete with others. The Verge. https://www.theverge.com/2012/2/22/2816583/nike-plus-basketball-training-shoes-app. Accessed 11 Feb 2020

12. De Rossi D, Bartalesi R, Lorussi F, Tognetti A, Zupone G (2006) Body gesture and posture classification by smart clothes. In: Proceedings of the First IEEE/RAS-EMBS International Conference on Biomedical Robotics and Biomechatronics, 2006, BioRob 2006, pp. 1189-1193. Pisa, Italy

13. Dellinger AJ (2020) Self-drying jacket means you'll never fear rainy days again. Daily Dot. https://www. dailydot.com/debug/self-drying-rain-jacket/. Accessed 1 Feb 2020

14. Dunne L (2010) Smart clothing in practice: key design barriers to commercialization. Fash Pract 2(1):4165. https://doi.org/10.2752/175693810X12640026716393

15. Dunne L, Smyth B (2007) Psychophysical elements of wearability. In: Proceedings of the International Conference on Human Factors in Computing Systems (SIGCHI), San Jose, CA: ACM Press. San Jose, California, USA, pp 299-302

16. Ebling MR (2016) IoT: from sports to fashion and everything in-between. IEEE Pervasive Comput 15(4):24. https://doi.org/10.1109/MPRV.2016.71

17. Frango PMVL, Postolache O (2018) Mobile application based on wireless sensor network for physical rehabilitation. In: Proceedings of the 2018 International Symposium in Sensing and Instrumentation in IoT Era (ISSI), Shanghai, China: ISSI 2018. https://doi.org/10.1109/ISSI.2018.8538145 
18. Gellersen HW, Schmidt A, Beigl M (2002) Multi-sensor context-awareness in mobile devices and smart artifacts. Mob Netw Appl 7:341-351. https://doi.org/10.1023/A:1016587515822

19. Gepperth J (2012) Smart things: wearables \& clothing. CiteSeerX. http://citeseerx.ist.psu.edu/viewdoc/ download?doi=10.1.1.394.9122\&rep=rep1\&type=pdf\#page=47. Accessed 11 Feb 2020

20. Goulev P, Mamdani E (2004) Utilizing real time affective sensors to incorporate emotions into human computer interactions. In: Proceedings of the International Workshop on Wearable and Implantable Body Sensor, Networks, pp. 6-7. London, UK

21. Hegde N, Melanson E, Sazonov E (2016) Development of a real time activity monitoring android application utilizing SmartStep, in: The 38th Annual International Conference of the IEEE Engineering in Medicine And Biology Society (EMBC): IEEE, pp 1886-1889. Orlando, Florida, USA. https://doi.org/10. 1109/EMBC.2016.7591089

22. Horvat I, Lukac N, Pavlovic R, Starcevic D (2015) Smart plug solution based on Bluetooth low energy. In: Proceedings of the 2015 IEEE 5th International Conference On Consumer Electronics - Berlin (ICCEBerlin), Berlin, Germany, IEEE 2015. https://doi.org/10.1109/ICCE-Berlin.2015.7391301

23. Hwang CG (2014) Consumers' acceptance of wearable technology: examining solar-powered clothing (Master's thesis, Iowa State University). Iowa State University Digital Repository. Retrieved from https:// lib.dr.iastate.edu/etd/13950/. Accessed 11 Feb 2020

24. Karras A (2017) Wearable tech just got weirder: introducing the virtual hug shirt. Sunday Times https:// www.timeslive.co.za/sunday-times/lifestyle/fashion-and-beauty/2017-08-28-wearable-tech-just-gotweirder-introducing-the-virtual-hug-shirt/. Accessed 11 Feb 2020

25. Lee HS (2020) A study on the development of a user-focused multi-functional convergence-smart-fashion product. Heliyon 6(1):1-17. https://doi.org/10.1016/j.heliyon.2019.e03130

26. Lee HS, Lee JJ (2018) A study on the development of the functional convergence fashion prototype applied the low-tech -focused on the convergence between fashion and electronic technology. J Korean Soc Costume 68(2):98-115

27. Lee HS, Lee JJ (2019) A study on the development of wearable smart fashion product -focused on the construction of optimized functionalities for particular needs. Fashion \& Textile Research Journal 21(2): 133-140. https://doi.org/10.5805/SFTI.2019.21.2.133

28. Li Y, Xue F, Fan X, Qu Z, Zhou G (2018) Pedestrian walking safety system based on smartphone built-in sensors. IET Commun 12(6):751-758. https://doi.org/10.1049/iet-com.2017.0502

29. Li Y, Peng X, Zhou G, Zhao H (2020) SmartJump: a continuous jump detection framework on smartphones. IEEE Internet Comput 24(2):18-26. https://doi.org/10.1109/mic.2020.2969610

30. Ma YC, Chao YP, Tsai TY (2013) Smart-clothes - prototyping of a health monitoring platform. In Proceedings of the 2013 IEEE Third International Conference on Consumer Electronics, pp 60-63. Berlin, Germany. https://doi.org/10.1109/ICCE-Berlin.2013.6698063

31. Majeed MAA, Rupasinghe TD (2017) Internet of things (IoT) embedded future supply chains for industry 4.0: an assessment from an ERP-based fashion apparel and footwear industry. Int J Supply Chain Manag $6(1): 25-40$

32. Mann S (1997) Smart clothing: the wearable computer and wearcam. Pers Ubiquit Comput 1(1):21-27. https://doi.org/10.1007/BF01317885

33. Mazzoldi A, De Rossi D, Lorussi F, Scilingo EP, Paradiso R (2002) Smart textiles for wearable motion capture systems. AUTEX Res J 2(4):199-203

34. McCrindle RJ, Williams VM, Victor CR et al (2011) Wearable device to assist independent living. Int J Disabil Hum Dev 10(4):349-354. https://doi.org/10.1515/IJDHD.2011.052

35. McDonald JW, Henrie AM, Teramoto M, Medina E, Willick SE (2017) Descriptive epidemiology, medical evaluation, and outcomes of rock climbing injuries. Wilderness Environ Med 28(3):185-196. https://doi. org/10.1016/j.wem.2017.05.001

36. Miller MC, Mair H (2019) Between space and place in mountaineering: navigating risk, death, and power. Tour Geogr 22(2):354-369. https://doi.org/10.1080/14616688.2019.1654538

37. Myint CZ, Barsoum N, Ing WK (2010) Design a wearable device for blood oxygen concentration and temporal heart beat rate. AIP Conf Proc 1239(1):213-219. https://doi.org/10.1063/1.3459752

38. Ortner SB (1997) Thick resistance: death and cultural construction of agency in Himalayan mountaineering. Representations (Berkley) 59:135-162. https://doi.org/10.2307/2928818

39. Ortner SB (1999) Life and death on Mt. Everest: Sherpas and Himalayan mountaineering. Princeton University Press, Princeton, NJ, USA

40. Park JA, Han HJ, Heo JC, Lee JH (2017) Computer aided diagnosis sensor integrated outdoor shirts for real time heart disease monitoring. Computer Assisted Surgery 22(sup1):176-185. https://doi.org/10.1080/ 24699322.2017.1389396 
41. Porjazoski M, Latkoski P, Popovski B (2019) Bluetooth low energy-based smart home android solution. In: IEEE EUROCON 2019 -18th International Conference on Smart Technologies, IEEE. Novi Sad, Serbia. https://doi.org/10.1109/EUROCON.2019.8861866

42. Quinn B (2002) Techno fashion. Berg Publishers, New York

43. Sabine S (2008) Fashionable technology: the intersection of design, fashion, science, and technology. Springer Wien, Vienna, Austria

44. Sayeed TS, Rayhan T, Chowdhury S (2018) Bluetooth Low Energy (BLE) based portable medical sensor kit platform with cloud connectivity. In: 2018 International Conference on Computer, Communication, Chemical, Material and Electronic Engineering (IC4ME2). IEEE. Rajshahi, Bangladesh. https://doi.org/10. 1109/IC4ME2.2018.8465645

45. Seigneur V (2006) The problem of the defining the risk: the case of mountaineering. Forum qualitative Sozialforschung 7(1):245-256. https://doi.org/10.17169/fqs-7.1.65

46. Sportstechie (2014) Kolon sport life tech extreme environment smart jacket system designed by Seymourpowell. Sports Techie. https://sportstechie.net/kolon-sport-life-tech-extreme-environment-smartjacket-system-designed-by-seymourpowell/. Accessed 11 Feb 2020

47. Statt N (2016) Lenovo made a smart running shoe you can use as a mobile game controller. The Verge. https://www.theverge.com/2016/6/9/11897456/lenovo-smart-running-shoe-wearable-tech-world-2016. Accessed 11 Feb 2020

48. Such O, Muehlsteff $\mathrm{J}$ (2006) The challenge of motion artifact suppression in wearable monitoring solutions. In: Proceedings of the IEEE Engineering in Medicine and Biology Conference, New York: IEEE Computer Society, pp. 49-52. New York, USA

49. Suh S-E, Roh J-S (2015) A study on smart fashion product development trends. Res J Costume Cult 23(6): 1097-1115. https://doi.org/10.7741/rjcc.2015.23.6.1097

50. Toney A, Dunne L, Thomas BH, Ashdown SP (2003) A shoulder pad insert vibrotactile display. In: Proceedings of the Seventh IEEE International Symposium On Wearable Computers (ISWC03), IEEE Computer Society, pp. 35-44. White Plains, New York, USA

51. Van Laerhoven K, Schmidt A, Gellersen HW (2002) Multi-sensor context aware clothing. In: Proceedings of the Sixth IEEE International Symposium on Wearable Computers, Seattle, WA: IEEE Computer Society. Washington, USA, pp 49-56

52. Wang Z, Yang Z, Dong T (2017) A review of wearable technologies for elderly care that can accurately track indoor position, recognize physical activities and monitor vital signs in real time. Sensors 17(2):341. https://doi.org/10.3390/s17020341

53. Watson A, Lyubovsky A, Koltermann K, Zhou G (2021) Magneto: joint angle analysis using an electromagnet-based sensing method. In: Proceedings of the 20th International Conference on Information Processing in Sensor Networks (co-located with CPS-IoT Week 2021), Nashville: Association for Computing Machinery, pp. 1-14. Nashville, Tennessee, USA

54. Weir J (2007) Burton-Motorola Audex jacket. CRUNCHWEAR. https://crunchwear.com/burton-motorolaaudex-jacket/. Accessed 1 Feb 2020

55. Weir J (2012) Electricfoxy's the move electronic yoga suit lets you know when you are contorting yourself incorrectly. CRUNCHWEAR. https://crunchwear.com/electricfoxys-the-move-electronic-yoga-suit-letsyou-know-when-you-are-contorting-yourself-incorrectly/. Accessed 11 Feb 2020.

56. Yang JS, Kim JY (2014) A case study on the wearable device in the new media age -focused on the portable device. J Korean Soc Des Cult 20(2):354-364

57. Yoon SI, Kang HS (2013) The type and development of hybrid fashion's convergence - focused on convergence of 21st century technology and design. Journal of Korea Design Forum 38:299-308

Publisher's note Springer Nature remains neutral with regard to jurisdictional claims in published maps and institutional affiliations.

Hyunseung Lee Assistant Professor, Dept. of Fashion Industry, Incheon National University. PhD Dept. of Fashion Design, Graduation School of Techno Design, Kookmin University, MA. Applied Imagination in the Creative Industries, Central Saint Martins, University of Art, London.

Kyungsoon Baek Researcher, Modular Smart Fashion Platform Research Center, Kookmin University. MA, Dept. of Computer Science, Graduation School of Kookmin University, Kookmin University. 